\title{
Experimental Study on Damage and Failure of Coal-Pillar Dams in Coal Mine Underground Reservoir under Dynamic Load
}

\author{
Qiangling Yao $\mathbb{D},{ }^{1,2}$ Liqiang Yu $\mathbb{D}^{1,2}$ Ning Chen, ${ }^{1,2}$ Weinan Wang, ${ }^{1,2}$ and Qiang Xu $\mathbb{D}^{1,2}$ \\ ${ }^{1}$ State Key Laboratory of Coal Resource and Safe Mining, China University of Mining \& Technology, Xuzhou 221116, China \\ ${ }^{2}$ School of Mines, China University of Mining \& Technology, Xuzhou 221116, China \\ Correspondence should be addressed to Liqiang Yu; yuliqiangcumt@163.com
}

Received 17 April 2021; Accepted 7 June 2021; Published 1 July 2021

Academic Editor: Yu Wang

Copyright (C) 2021 Qiangling Yao et al. This is an open access article distributed under the Creative Commons Attribution License, which permits unrestricted use, distribution, and reproduction in any medium, provided the original work is properly cited.

\begin{abstract}
The stability of coal-pillar dams in underground hydraulic engineering works is affected not only by long-term water erosion but also by dynamic loading induced, for example, by roof breaking or fault slipping. In this paper, the water absorption characteristics of coal samples from western China were studied by nondestructive immersion tests, and a high-speed camera was used to monitor SHPB tests on samples of varying water content and subjected to various strain rates. Besides, the coal-pillar dam is numerically simulated based on the experimental data and the actual engineering conditions. The results show that, given low strain rate and high water content, the compaction stage accounts for most of the stress-strain curve, whereas the elastic stage accounts for only a relatively small fraction of the stress-strain curve. The dynamic compressive strength and elastic modulus follow exponential and logarithmic functions of strain rate, respectively, exhibiting a significant positive correlation. As the water content increases, the dynamic elastic modulus increases almost linearly, and the compressive strength decreases gradually. Under the same impact load, samples with greater water content fail more rapidly, and the failure is exacerbated by the propagation of parallel cracks to staggered cracks. The average size of coal fragments decreases linearly with increasing strain rate and water content. Simulations indicate that dynamic loading increases the stress concentration on both sides of the dam and expands the highstress area and plastic zone. The results provide guidance for designing waterproof coal pillars and underground reservoir dams.
\end{abstract}

\section{Introduction}

The focus of China's strategy for coal resources has gradually shifted to the central and western regions of China [1]. In 2020, although the coal output of Shanxi, Shaanxi, Inner Mongolia, Xinjiang, and Ningxia accounted for $80.4 \%$ of the total coal output in China [2], the water resources in those areas were quite deficient, accounting for less than $6.6 \%$ of the national total. The contradiction between coal and water resources is thus becoming increasingly prominent in western China. To alleviate the imbalance between the supply and demand of water resources in these areas, coal pillars may be used to connect the artificial dams and to build underground reservoirs in goaf to store water [3,4]. Coalpillar dams are an important part of underground reservoirs and are affected not only by long-term water erosion but also by dynamic loading disturbances caused, for example, by roof breaking or fault slipping during mining. Thus, the study of the damage characteristics of water-containing coal samples under dynamic loading can improve evaluations of the stability and the design of coal-pillar dams and help to unravel the failure mechanisms of coal subjected to dynamic loading disturbances.

Since the proposal of water-rock interactions in the 1950s, various studies have investigated this phenomenon and have significantly advanced the field [5]. Uniaxial compression tests on coal-rock samples with different water contents show that their compressive strength, elastic modulus, and Poisson ratio decrease as the water content increases $[6,7]$. Shear and creep tests on dry and water-containing rock samples show that water infiltration improves the creep strain and strain rate but decreases the strength [8-10]. Vásárhelyi [11] applied splitting-tensile tests to 45 dry and saturated limestone samples and showed that the strength of saturated rock is 0.659 times that of its dry counterpart. In addition, rock samples under different water-absorbing 


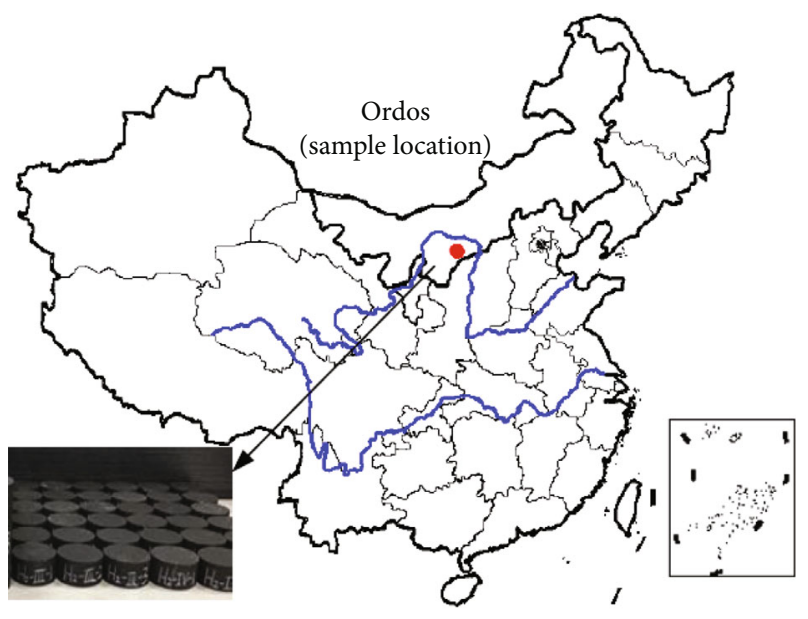

Figure 1: Coal samples used in this work.

TABLE 1: Sample numbering system.

\begin{tabular}{lcccc}
\hline Label & $\mathrm{W} 1$ & $\mathrm{~W} 2$ & $\mathrm{~W} 3$ & - \\
Water contents & 0 & $5.79 \%$ & $12.53 \%$ & - \\
Label & $\mathrm{W} 1-\mathrm{V} 1$ & $\mathrm{~W} 1-\mathrm{V} 2$ & $\mathrm{~W} 1-\mathrm{V} 3$ & $\mathrm{~W} 1-\mathrm{V} 4$ \\
Air pressure & $0.1 \mathrm{MPa}$ & $0.2 \mathrm{MPa}$ & $0.3 \mathrm{MPa}$ & $0.4 \mathrm{MPa}$ \\
Label & $\mathrm{W} 1-\mathrm{V} 1-1$ & $\mathrm{~W} 1-\mathrm{V} 1-2$ & $\mathrm{~W} 1-\mathrm{V} 1-3$ & - \\
Number & No. 1 & No. 2 & No. 3 & - \\
\hline
\end{tabular}

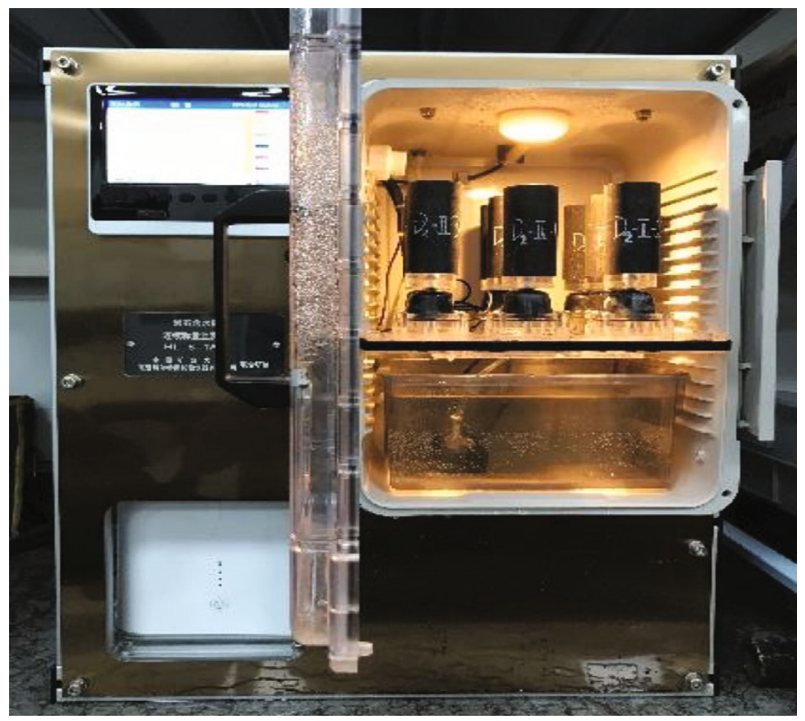

FIgURE 2: Nondestructive immersion device.

conditions were subjected to triaxial compression tests [12, 13]. Yao et al. [ $[7,14,15]$ developed a nondestructive immersion device to study how coal pillars subjected to repeated water immersion are damaged and to understand the mechanical damage and acoustic emissions of coal samples subjected to wet-dry cycles. Xia et al. [16] used uniaxial compression tests and acoustic-emission monitoring to investigate how immersion time affects diorite and established a rock-damage model that takes into account how immersion time affects the acoustic-emission characteristics. Gu et al. [17] used similarity model tests and numerical simulations to compare and analyze the seismic safety of ground versus underground reservoirs and subsequently proposed the notion of the safety factor for underground reservoir dams in coal mines.

Studies of water-containing coal rock mainly consider the static mechanical performance while largely neglecting the dynamic mechanical performance [18]. However, mining activities involve many complex, nonnegligible dynamic issues [19], such as how dynamic loading affects the stability of coal-pillar dams. Currently, the load on the coal is categorized based on strain rate, but the standard used to distinguish between static load and dynamic load is not strictly determined [20]. In their review of research over the past decade into dynamic rock mechanics, Huang [21] considered only the effect of dynamic rock mechanics for strain rates in the range $0.1-10000^{-1}$. The split Hopkinson press bar (SHPB) is a typical dynamic-loading device used to study the characteristics of materials under high strain [22], and numerous studies have used it to determine the mechanical performance of rock subjected to dynamic loading. The results reveal that the static mechanical performance differs significantly from the dynamic mechanical performance [23, 24], which is closely related to the strain rate [25]. Shan et al. [26] performed dynamic impact experiments on anthracite coal and divided the resulting dynamic constitutive curve of rock into four stages. In addition, dynamic impact experiments involving bullets shot at different impact velocities at rock demonstrated that the dynamic compressive strength of rock depends strongly on strain rate [27, 28]. Jiang et al. [29] investigated the dynamic mechanical characteristics of black granite as a function of strain rate. The results show that, under high strain rate, the dynamic compressive strength of rock undergoes an abrupt jump, and its elastic deformation correlates negatively with strain rate. Fu et al. [30] clarified the dynamic failure mechanism of rock and constructed a viscoelastic constitutive model of a damaged body, finding that the dynamic strength and elastic modulus of the sample continue to increase with increasing strain whereas plastic deformation increases and then decreases. Liu et al. [31] reported that coal rock undergoes axial splitting failure when loaded at low strain rate and crushing failure when loaded at high strain rate and that the impact energy correlates positively with strain rate. Demirdag et al. [32] applied SHPB tests to various types of limestone and reported that porosity, hardness, and unit weight significantly affect the dynamic mechanical characteristics of rock.

At present, the study of the dynamic mechanical characteristics of materials focuses mainly on brittle materials such as sandstone and granite. The strength of coal is between that of hard rock and soft rock, and its dynamic response to highstrain-rate loading differs from that of other rock. In addition, water infiltration may significantly complicate its mechanical performance. However, despite these facts, investigations into the damage mechanisms of rock remain unclear, so further study is required. Thus, considering that water and high strain rate affect coal samples, the present study uses an independently developed nondestructive 


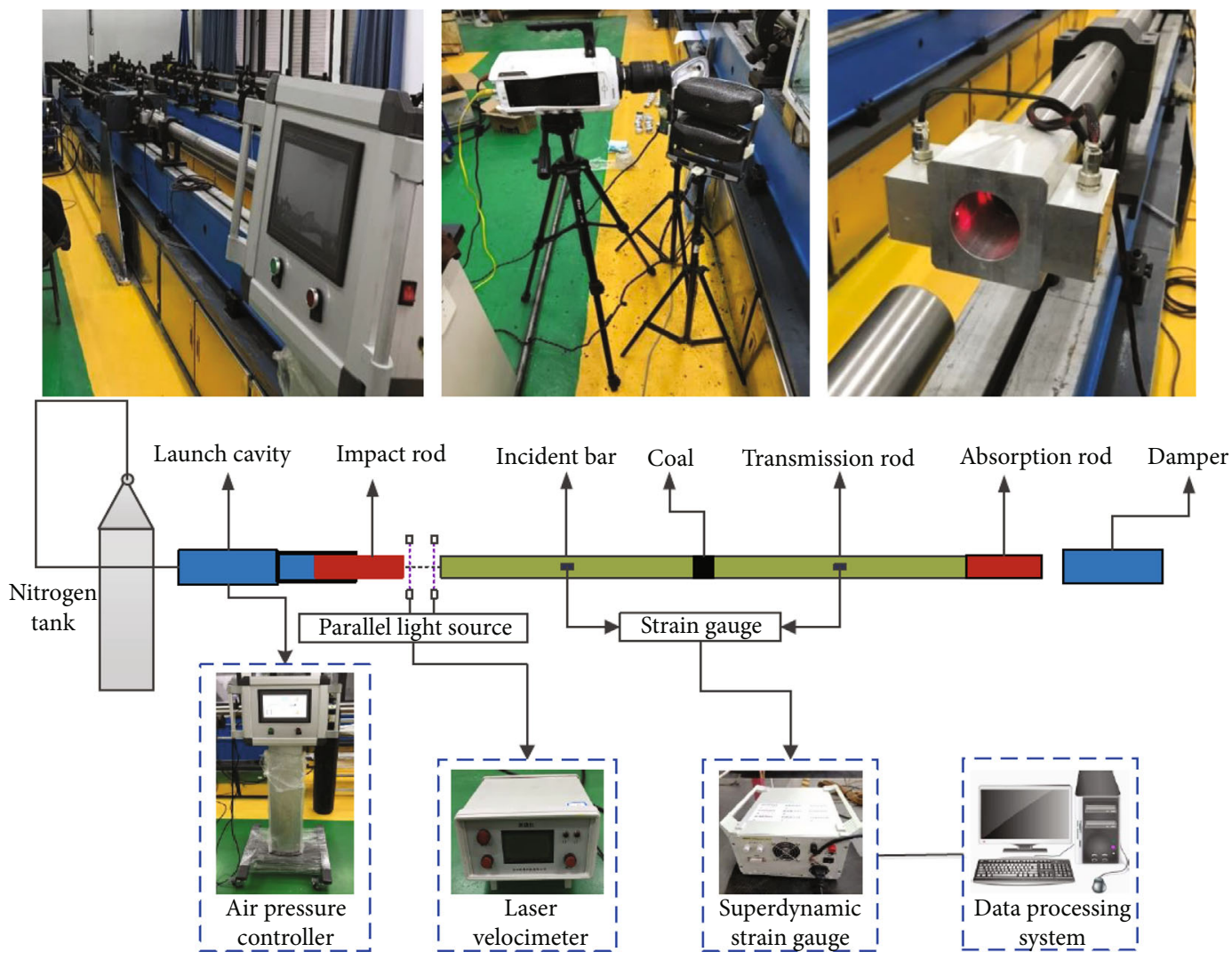

Figure 3: Dynamic loading test system.

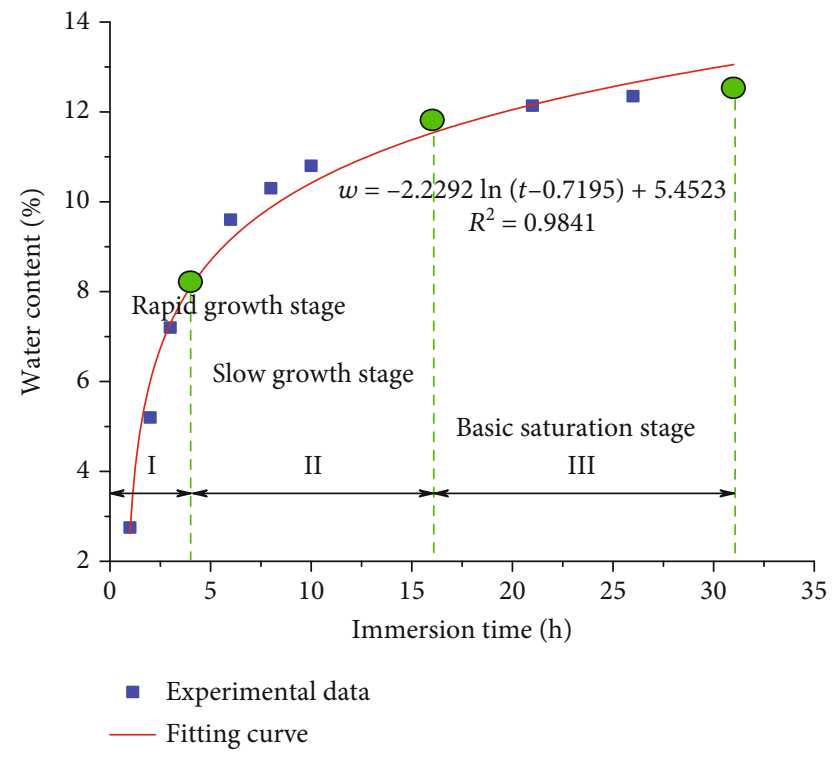

Figure 4: Water content as a function of coal sample immersion time.

immersion device to analyze how water content affects coal. By applying SHPB tests to coal samples of varying water content and strain rate, this study explores the mechanisms that cause dynamic mechanical damage, crack propagation, and failure in coal rock. The stability of coal-pillar dams is also analyzed by numerical simulations anchored by the test results and engineering practice. The results obtained should advance our understanding of the mechanisms of dynamic mechanical damage in water-containing coal samples and thereby provide guidance for the construction of coal-pillar dams.

\section{Materials and Methods}

2.1. Selection and Preparation of Coal Samples. Coal samples (see Figure 1) were taken from the coal-pillar dam (3-1 coal seam, average thickness $5.75 \mathrm{~m}$, immediate roof and immediate floor are sandy mudstone) in the Chahasu coal mine of the Xinjie mining area in the Dongsheng coalfield of the Shendong mine area, China. The samples were formed into cylindrical specimens with dimensions of $\Phi 50 \mathrm{~mm} \times 25 \mathrm{~mm}$ , and the integration was done following the Rock Testing Handbook from the International Society for Rock Mechanics [33] and Methods for Determining the Physical and Mechanical Properties of Coal and Rock [34]. Irregularity at both ends of the samples remained within $\pm 0.05 \mathrm{~mm}$, the end faces were perpendicular to the sample axis, and the axial alignment tolerance was within $\pm 0.25^{\circ}$. All coal samples were numbered based on their water content $w$ and air pressure $a$. The samples were organized into twelve groups of three, for a total number of 36 . Table 1 gives the details of the sample numbering system.

2.2. Experimental Apparatus and Method. The coal samples were dried in an air-circulation oven (Shanghai Instrument 
TABLE 2: The average impact velocity of the impingement rod and the average strain rate of coal samples under different pressure loading.

\begin{tabular}{lccccc}
\hline $\begin{array}{l}\text { Group } \\
\text { number }\end{array}$ & $\begin{array}{c}\text { Load pressure } \\
(\mathrm{MPa})\end{array}$ & $\begin{array}{c}\text { Water content } \\
(\%)\end{array}$ & $\begin{array}{c}\text { Average impact velocity } \\
(\mathrm{m} / \mathrm{s})\end{array}$ & $\begin{array}{c}\text { Average strain rate } \\
\left(\mathrm{s}^{-1}\right)\end{array}$ & $\begin{array}{c}\text { Group average strain rate } \\
\left(\mathrm{s}^{-1}\right)\end{array}$ \\
\hline W1-A1 & 0.1 & 0.00 & 5.01 & 43.06 \\
W2-A1 & 0.1 & 5.79 & 5.98 & 50.20 & 45.92 \\
W3-A1 & 0.1 & 12.53 & 6.05 & 44.51 & 50.73 \\
W1-A2 & 0.2 & 0.00 & 7.34 & 61.31 & 56.08 \\
W2-A2 & 0.2 & 5.79 & 7.74 & 70.18 & \\
W3-A2 & 0.2 & 12.53 & 7.62 & 69.25 & 68.38 \\
W1-A3 & 0.3 & 0.00 & 8.77 & 64.95 & 86.37 \\
W2-A3 & 0.3 & 5.79 & 8.67 & 87.22 \\
W3-A3 & 0.3 & 12.53 & 8.85 & 93.71 \\
W1-A4 & 0.4 & 0.00 & 10.06 & 13.10 \\
W2-A4 & 0.4 & 5.79 & 10.12 & 5.30 & \\
W3-A4 & 0.4 & 12.53 & &
\end{tabular}

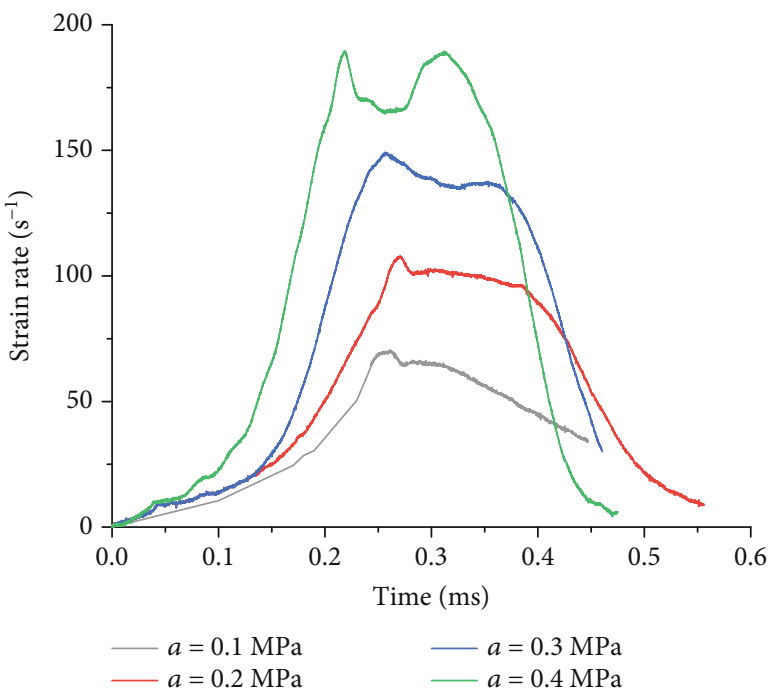

(a) Strain rate vs. time

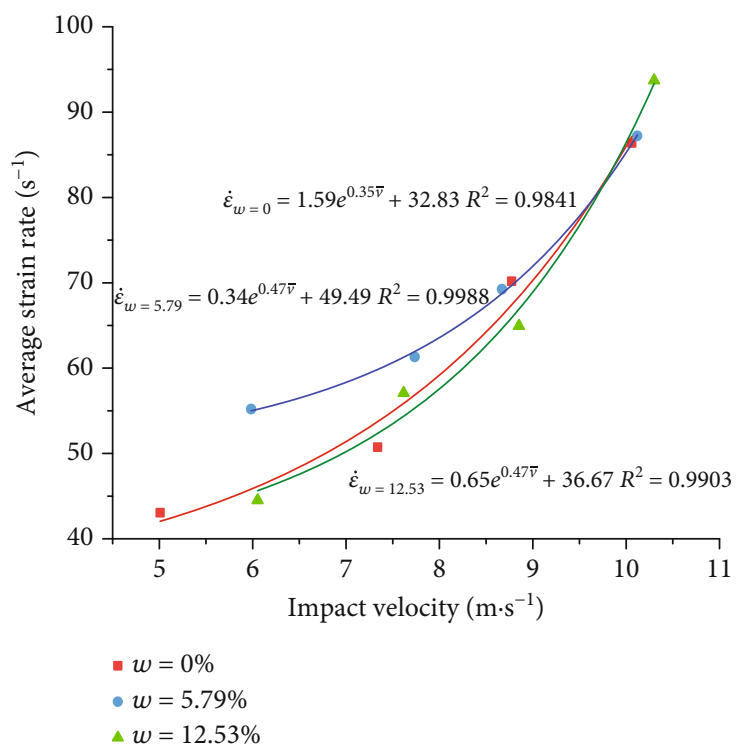

(b) Average strain rate vs. impact velocity

FIGURE 5: Strain rate as a function of time and water content.

Factory, model $101-2$, China) at $105^{\circ} \mathrm{C}$ for $12 \mathrm{~h}$ as per the Regulation for Testing the Physical and Mechanical Properties of Rock (DZ/T 0276.2-2015) [35]. An independently developed smart nondestructive immersion instrument (HL-8-1WS by China University of Mining and Technology and Dongying Kersite Test Instrument Co., Ltd.) [36] (see Figure 2) was used to immerse the coal samples. The instrument converts water into steam through an ultrasonic humidifier, and the steam is fed into the constant-temperature-and-humidity incubator along the internal pipe. The coal samples were in full contact with saturated-humidity steam in the constant-temperature-and-humidity incubator and allowed to freely absorb water, thereby avoiding the pressure-induced structural damage that can occur when samples are immersed in water and thus ensuring the integrity of the samples.
Figure 3 shows the multifunctional separated SHPB test system (Luoyang Liwei Science and Technology Co., Ltd., China, model LW19-09-3) used as loading system, which allowed us to modify the impact velocities of bullets by changing the air pressure $(0.1,0.2,0.3$, or $0.4 \mathrm{MPa})$ to achieve different strain rates. A high-speed camera recorded the damage and failure of the coal samples. The entire system consisted of a loading system, pressure bar system, measuring system, and data-acquisition system. The impact rod, incident rod, transmission rod, and absorption rod were $0.4,3.0,3.0$, and $1.5 \mathrm{~m}$ long, respectively. The pressure bar was made of silicon manganese steel with a density of $7.85 \mathrm{~g} / \mathrm{cm}^{3}$ and an elastic modulus of $206 \mathrm{GPa}$. BX120-2AA resistance strain gauges were used to monitor the strain with reasonable accuracy. The data were recorded by using an Hd5960 superdynamic resistance signal acquisition instrument. 


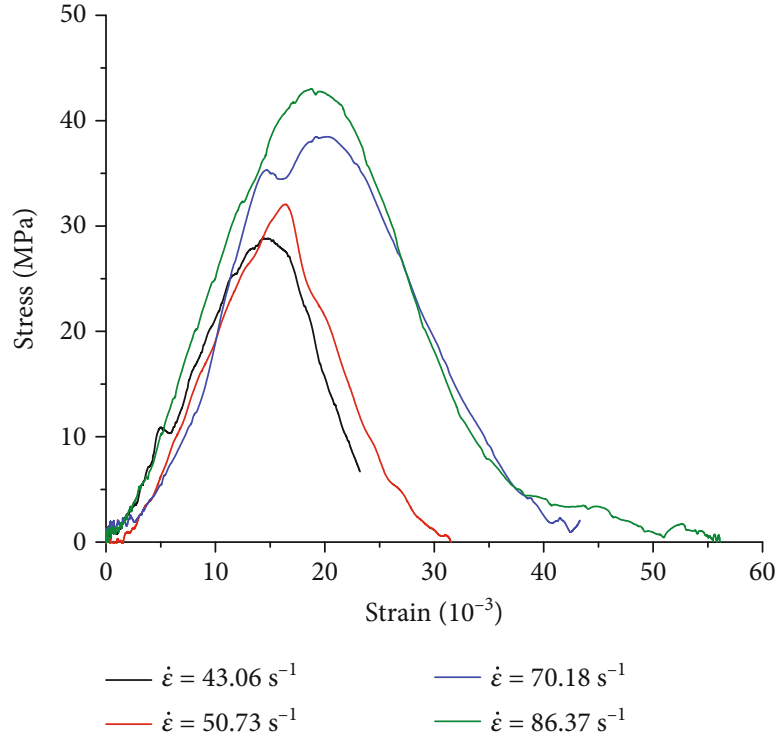

(a) $w=0 \%$

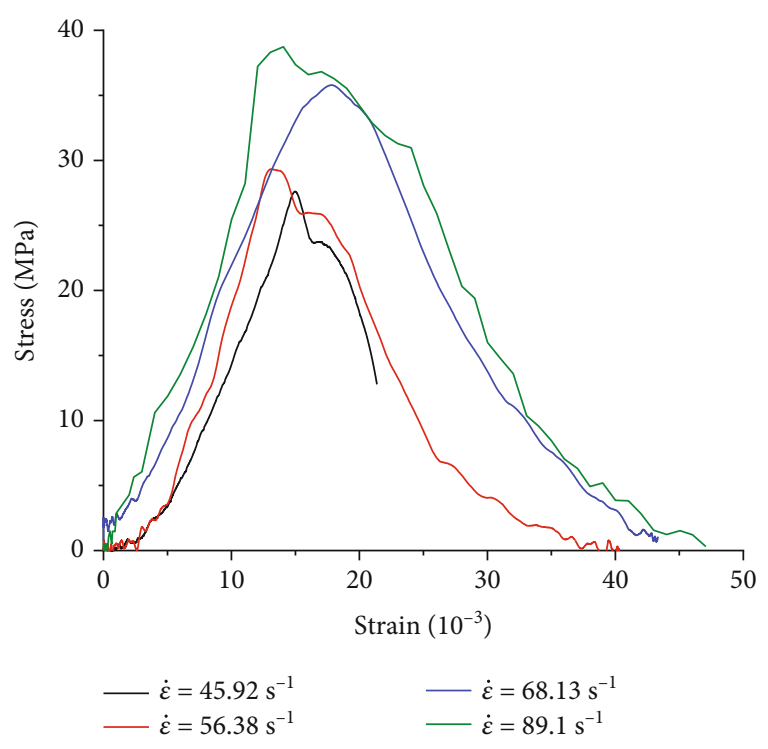

(b) $w=5.79 \%$

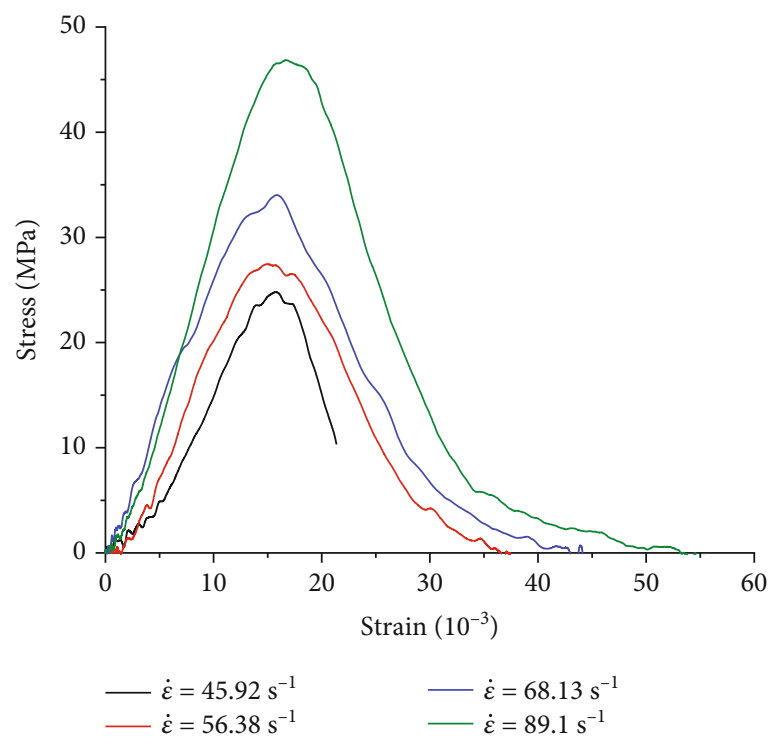

(c) $w=12.53 \%$

FIgure 6: Dynamic stress-strain curves of coal samples with different strain rates.

\section{Results and Analysis}

3.1. Water Absorption Characteristics of Coal Samples. Figure 4 shows the water content of the coal samples as a function of immersion time as determined by the nondestructive immersion tests. The slope of the curve (i.e., the water absorption rate of the coal sample) distinguishes three water absorption stages: (I) a rapidly increasing stage, (II) a slowly increasing stage, and (III) a near-saturation stage. From 0 to $5 \mathrm{~h}$, the water content of coal samples, which were initially dry, increased dramatically once coming in contact with water $(15.6 \%$ of the immersion time required for the coal sample to be saturated). From 5 to $16 \mathrm{~h}$, water gradually infiltrates into the samples until water absorption is complete [36], at which point the water absorption rate starts to decrease although the water content continues to increase.
From 16 to $32 \mathrm{~h}$, the coal sample is almost saturated, the absorption rate is near zero, and the water content remains constant. After $32 \mathrm{~h}$, the coal samples are saturated with a water content of $12.53 \%$.

The water contents of the coal samples follow a logarithmic function of immersion time:

$$
\begin{aligned}
w & =-2.2293 \ln (t-0.7195)+5.4523, \\
R^{2} & =0.9841,
\end{aligned}
$$

where $w$ is water content (\%), $t$ is immersion time (h), and $R^{2}$ is the square of the correlation coefficient of the fit. $R^{2} \approx 1$, which is indicative of a good fit, so this fit can serve as a good benchmark for studying the mechanical characteristics of 
TABle 3: Dynamic mechanical parameters of coal samples.

\begin{tabular}{lccccccccc}
\hline Group number & $w(\%)$ & $a\left(\mathrm{~s}^{-1}\right)$ & $\sigma_{\mathrm{c}}(\mathrm{MPa})$ & $E(\mathrm{GPa})$ & Group number & $w(\%)$ & $a\left(\mathrm{~s}^{-1}\right)$ & $\sigma_{\mathrm{c}}(\mathrm{MPa})$ & $E(\mathrm{GPa})$ \\
\hline W1-A1-1 & 0 & 43.06 & 28.83 & 2.25 & W2-A3-1 & 5.73 & 69.247 & 35.79 & 3.58 \\
W1-A1-2 & 0 & 43.06 & 29.21 & 2.23 & W2-A3-2 & 5.73 & 69.247 & 35.49 & 3.52 \\
W1-A1-3 & 0 & 43.06 & 28.26 & 2.11 & W2-A3-3 & 5.73 & 69.247 & 34.12 \\
W1-A2-1 & 0 & 50.732 & 32.06 & 2.41 & W2-A4-1 & 5.73 & 87.216 & 36.84 & 3.47 \\
W1-A2-2 & 0 & 50.732 & 32.47 & 2.59 & W2-A4-2 & 5.73 & 87.216 & 36.91 \\
W1-A2-3 & 0 & 50.732 & 32.11 & 2.45 & W2-A4-3 & 5.73 & 87.216 & 37.31 \\
W1-A3-1 & 0 & 70.182 & 38.48 & 3.33 & W3-A1-1 & 12.53 & 44.511 & 24.80 \\
W1-A3-2 & 0 & 70.182 & 40.32 & 3.62 & W3-A1-2 & 12.53 & 44.511 & 23.64 \\
W1-A3-3 & 0 & 70.182 & 39.46 & 3.52 & W3-A1-3 & 12.53 & 44.511 & 24.13 \\
W1-A4-1 & 0 & 86.373 & 43.03 & 3.61 & W3-A2-1 & 12.53 & 57.083 & 27.47 \\
W1-A4-2 & 0 & 86.373 & 47.81 & 4.35 & W3-A2-2 & 12.53 & 57.083 & 30.32 \\
W1-A4-3 & 0 & 86.373 & 44.69 & 3.75 & W3-A2-3 & 12.53 & 57.083 & 31.21 \\
W2-A1-1 & 5.73 & 50.203 & 27.61 & 2.44 & W3-A3-1 & 12.53 & 64.946 & 34.02 \\
W2-A1-2 & 5.73 & 50.203 & 27.69 & 2.51 & W3-A3-2 & 12.53 & 64.946 & 3.14 \\
W2-A1-3 & 5.73 & 50.203 & 27.51 & 2.42 & W3-A3-3 & 12.53 & 64.946 & 3.22 \\
W2-A2-1 & 5.73 & 61.314 & 29.33 & 2.94 & W3-A4-1 & 12.53 & 93.713 & 46.83 \\
W2-A2-2 & 5.73 & 61.314 & 30.13 & 3.05 & W3-A4-2 & 12.53 & 93.713 & 42.34 \\
W2-A2-3 & 5.73 & 61.314 & 30.56 & 3.13 & W3-A4-3 & 12.53 & 93.713 & 44.31 & 3.75 \\
\hline
\end{tabular}

Note: $w$ : water contents; $a$ : air pressure; $\sigma_{c}$ : compressive strength; $E$ : elastic modulus.

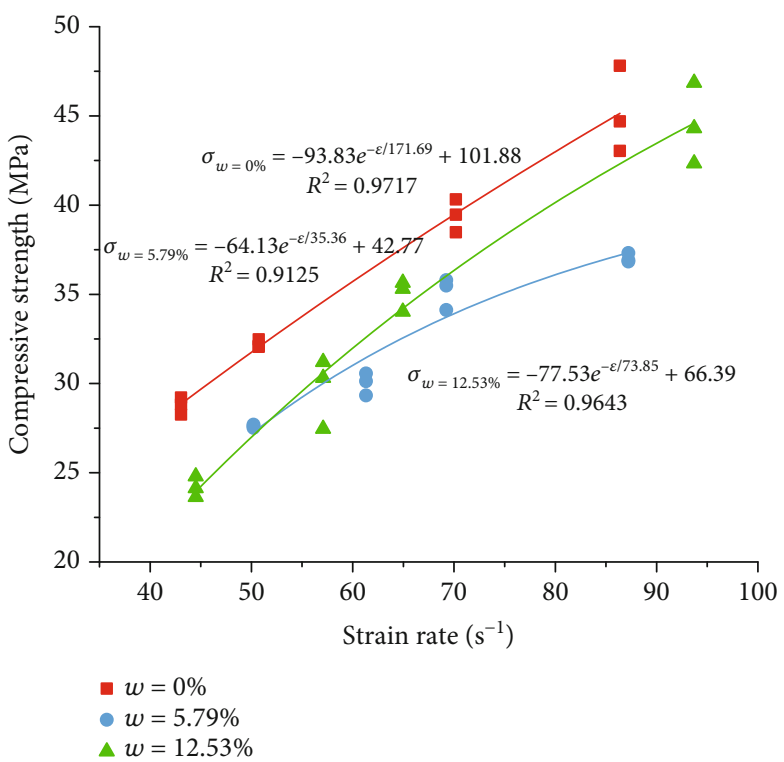

(a) Compressive strength vs. strain rate

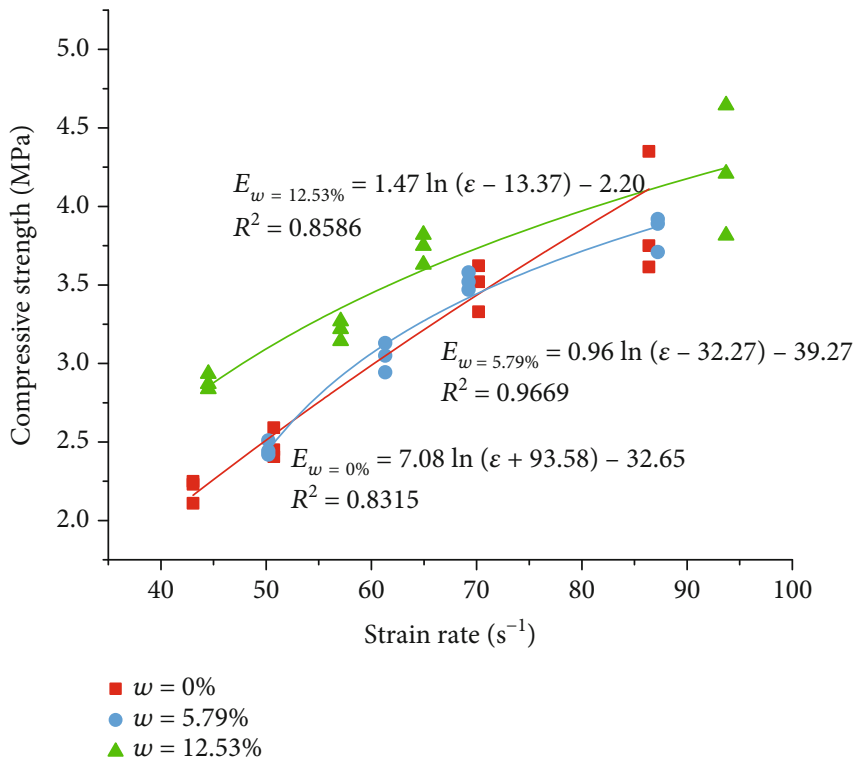

(b) Elastic modulus vs. strain rate

FIgURE 7: Dynamic compressive strength and elastic modulus as a function of the strain rate of coal samples.

water-containing coal samples. In the following analysis, we use the water contents of $0 \%, 5.79 \%$, and $12.53 \%$.

3.2. Variation in Strain Rate of Coal Samples. To study the dynamic characteristics of water-containing coal samples at different strain rates, the strain rate was varied in the coal samples by varying the air pressure and thereby the impact velocity of the bullets. Table 2 lists the resulting strain rates imparted to coal samples with three water contents $(0 \%$,
$5.79 \%$, and $12.53 \%$ ) and for air pressures of $0.1,0.2,0.3$, and $0.4 \mathrm{MPa}$.

Figure 5(a) shows the strain rate as a function of time in coal samples with water content of $0 \%$ and for different air pressures. Under an impact load, the strain rate of the coal samples changes continuously over time (more specifically, it increases and then decreases over the entire process of loading and unloading). The bullet impact velocity increases with air pressure, and the rate of change in strain and peak 


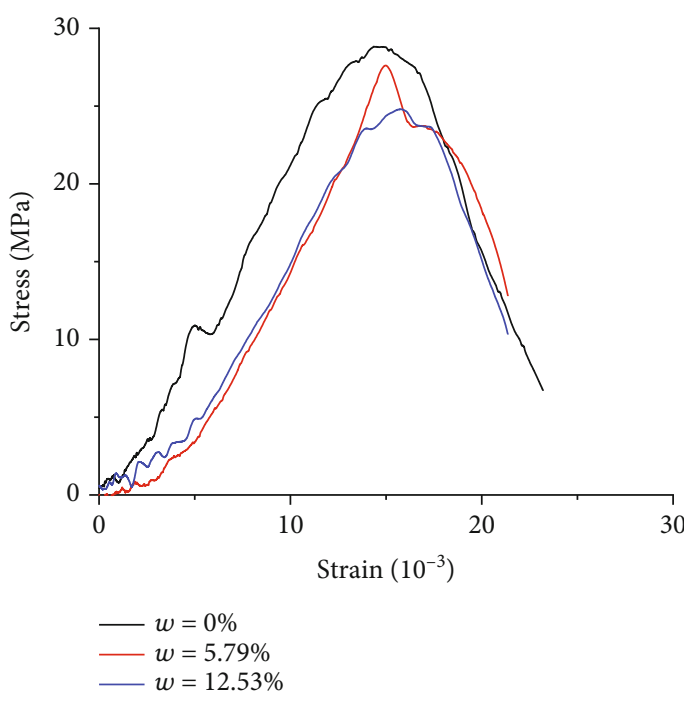

(a) $\dot{\varepsilon}=45.92 \mathrm{~s}^{-1}$

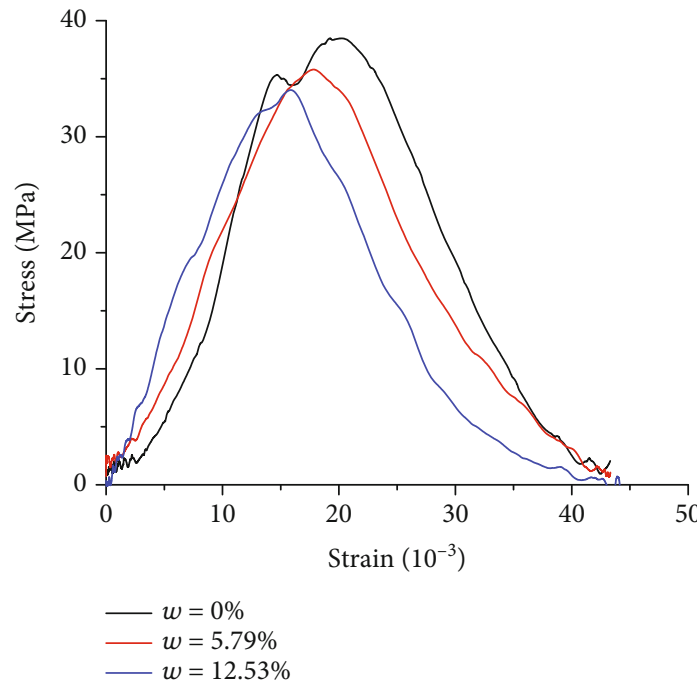

(c) $\dot{\varepsilon}=68.13 \mathrm{~s}^{-1}$

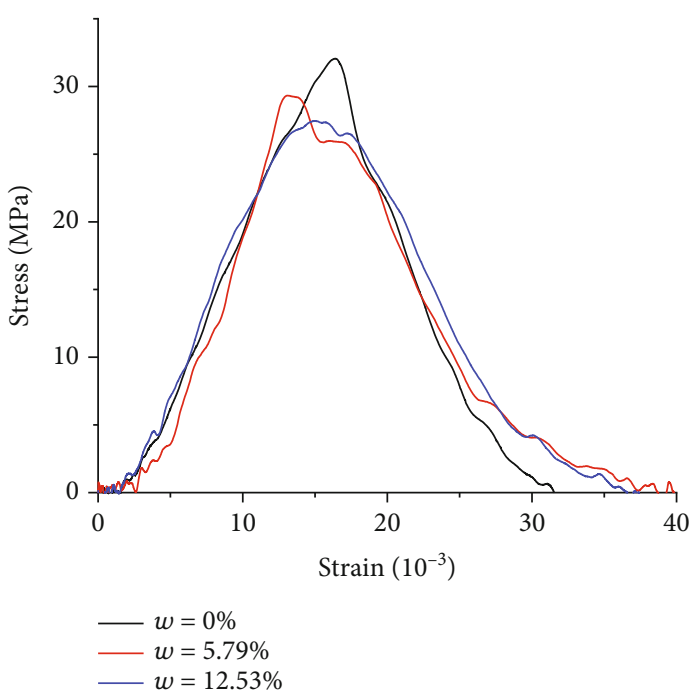

(b) $\dot{\varepsilon}=56.38 \mathrm{~s}^{-1}$

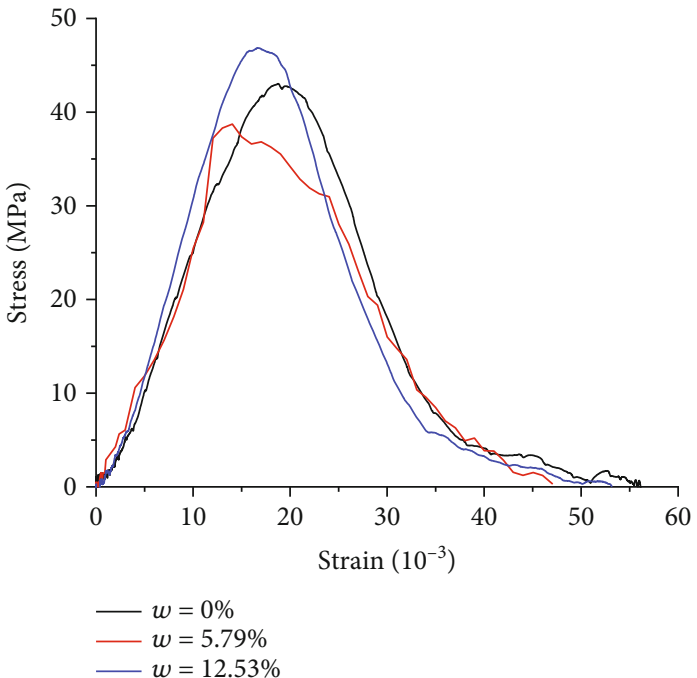

(d) $\dot{\varepsilon}=89.10 \mathrm{~s}^{-1}$

Figure 8: Dynamic stress-strain curves of coal samples with different water contents.

strain also both increases. Thus, the time required for the coal sample to reach its peak strain rate is shortened. The large impact load induced by the high air pressure closes the cracks, which protects the coal sample from unloading failure and significantly increases the strain rate. Notably, the strain rates of coal samples decreased and then increased after reaching their peaks. Herein, the strain rates were stabilized at relatively high levels and both stresses and strains varied drastically, resulting in strain hardening of samples [37]. The greater the loading pressure, the more obvious the strain hardening.

Figure 5(b) shows the average strain rate and impact velocity of coal samples as a function of water content. As the impact velocity increases, the strain rate of the watercontaining coal samples continues to increase in an exponential manner. The larger the water content becomes, the more sensitive the strain rate becomes to impact rate, and the more significant is the change in strain rate. Exponential fits to these curves give the exponents $N_{w=0}=0.3511, N_{w=5.49}=$ 0.4660 , and $N_{w=12.53}=0.4739$. These results suggest that water erosion weakens the coal samples, thereby causing significant changes in sample strain under dynamic loading. Additionally, given the data in Table 2 and the effect of water content and heterogeneity on the coal samples, the strain rates under a given air pressure differ only slightly. Therefore, for convenience, the average strain rate is used in the analysis.

3.3. Damage to Coal Samples as a Function of Strain Rate. Figure 6 shows the dynamic stress-strain curves of watercontaining coal samples for different strain rates, and Table 3 gives the dynamic mechanical parameters. Similar to the stress-strain curves of coal subjected to static loading $[38,39]$, these curves can be divided into five stages: (I) the first stage is the fracture-compression stage, where the curve is concave upward. In this stage, the internal pores and cracks start to close, the defect structure shrinks, and the 


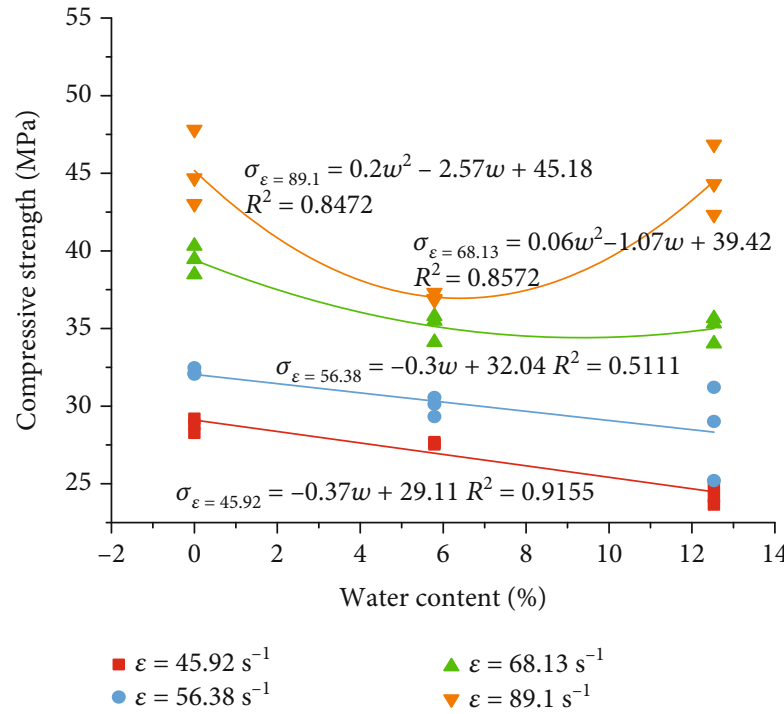

(a) Compressive strength vs. water content

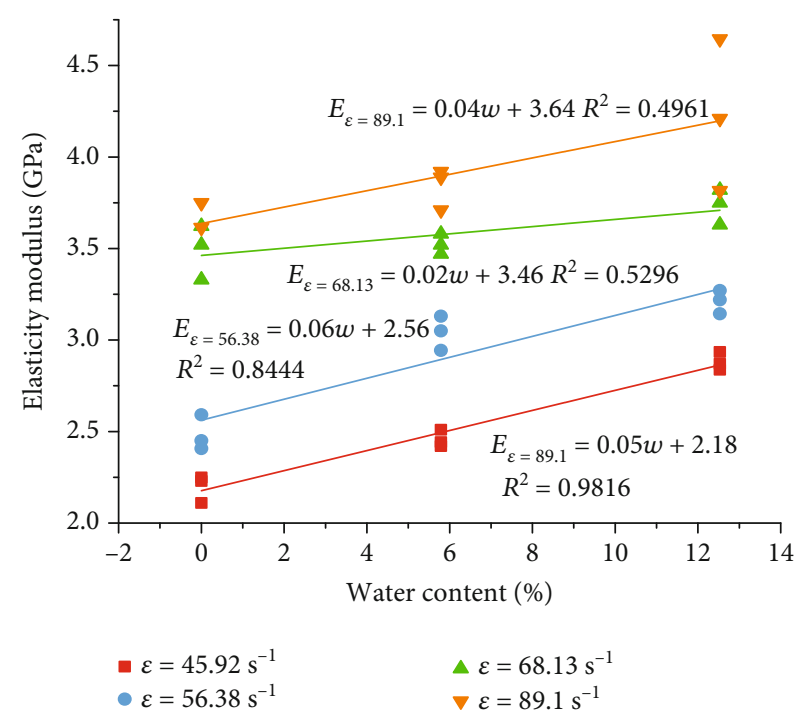

(b) Elastic modulus vs. water content

FIGURE 9: Dynamic compressive strength and elastic modulus of coal samples as functions of water content.

deformation bearing capacity of the sample gradually increases. Since the loading rate of the impact load far exceeds that of the static or quasistatic load, the internal cracks in the coal samples close fairly slowly, making this stage difficult to detect [40]. (II) In the elastic deformation stage, the coal sample stores elastic energy, the stress increases linearly with strain, and the slope of the curve is the dynamic elastic modulus. (III) This is the stable crackpropagation stage, where stress grows slowly with strain, and the stress-strain curve is concave downward. Cracks start propagating, and the coal samples are subject to significant axial compression and radial expansive deformation [41]. (IV) In the unstable crack-propagation stage, the original cracks rapidly propagate, connect, and link up, and the overall deformation resistance of the coal sample decreases considerably. At the end of the stage, the slope approaches zero, and stress attains its maximal value (at this point, the strain is called the "peak strain"). (V) The unloading stage occurs after the peak stress and is due to the axially connected cracks; the coal sample loses its bearing capacity, the capacity of pressure rods to hold coal samples and their stresses drop rapidly.

The stress-strain curves of coal samples at different strain rates vary significantly. At low strain rate, the fracturecompression stage encompasses a large portion of the curve before the peak stress. Consider as an example the coal sample with a water content of $12.53 \%$; the fracture-compression stage of this coal sample accounts for $34.04 \%$ of the total curve at the strain rate of $45.92 \mathrm{~s}^{-1}$, and as the strain rate increases, the portion of the curve accounted for by the fracture-compression stage decreases to $27.18 \%, 16.25 \%$, and $12.62 \%$ as the strain rate increases to $56.38,68.13$, and $89.10 \mathrm{~s}^{-1}$, respectively. When subject to a high strain rate, coal samples must withstand a higher impact load, causing the cracks inside to compress faster and thereby reducing the time for crack closure. This makes the fracture- compression stage of coal samples under a high strain rate become less evident. In contrast, as the strain rate increases, the elastic stage accounts for a larger portion of the curve before the peak. The elastic stage accounts for $61.07 \%$, $67.81 \%, 78.99 \%$, and $86.42 \%$ of the total curve when the strain rate is $45.92,56.38,68.13$, and $89.10 \mathrm{~s}^{-1}$, respectively, which are significant increments. Since more cracks are involved in the deformation when the strain rate is high, the deformation resistance of the sample increases [41].

Figure 7(a) shows the dynamic compressive strength of the coal samples as a function of strain rate. The dynamic compressive strength of the coal samples is an exponential function of strain rate. Consider as an example the dry coal samples: as the strain rate increases from 43.06 to $86.37 \mathrm{~s}^{-1}$, the average dynamic compressive strength increases from 28.77 to $32.21,39.42$, and $45.18 \mathrm{MPa}$ (increments of $10.70 \%, 18.28 \%$, and $12.75 \%$, respectively), displaying a significant positive correlation. This result is similar to the general result obtained for brittle rock $[27,28]$. From the energy perspective, numerous cracks and weak structural planes exist inside the coal samples, and the damage process under an impact load reflects the propagation process of structural defects, where energy absorption and loss occur. Although the consumption of energy during crack propagation requires an accumulation of energy, the extremely short duration of dynamic loading means that the coal sample does not have sufficient time to absorb and accumulate energy to sustain its carrying capacity. Therefore, the stress increases to offset the effect of the impact load, as reflected in the higher strength $[25,31]$.

Figure 7(b) shows the dynamic elastic modulus as a function of the strain rate of the coal samples. As the strain rate increases, the average elastic modulus of the coal sample with $w=0 \%$ increases from 2.20 to $2.48,3.49$, and $3.90 \mathrm{GPa}$ (increments of $12.73 \%, 40.73 \%$, and $11.75 \%$, respectively). For the coal sample with $w=5.79 \%$, the elastic modulus 


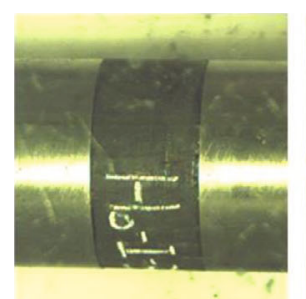

$90 \mu \mathrm{s}$

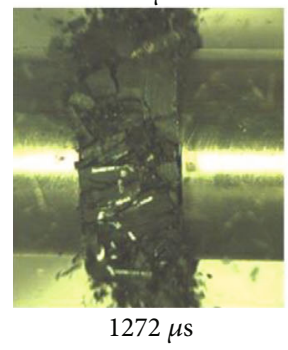

$1272 \mu \mathrm{s}$

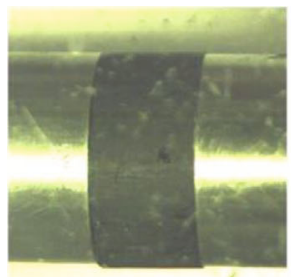

$72 \mu \mathrm{s}$

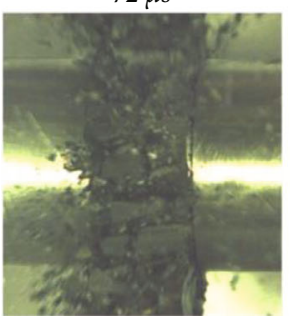

$1072 \mu \mathrm{s}$

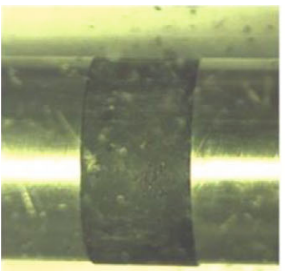

$45 \mu \mathrm{s}$

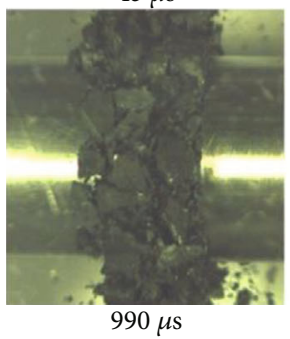

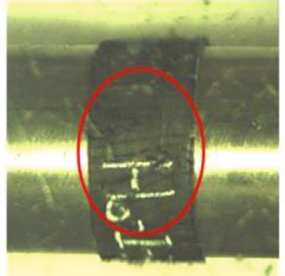

$545 \mu \mathrm{s}$

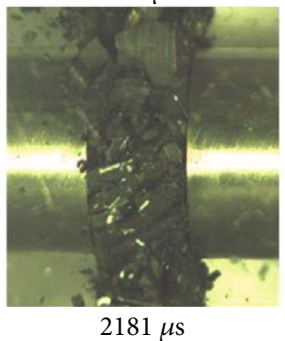

(a) $w=0 \%$

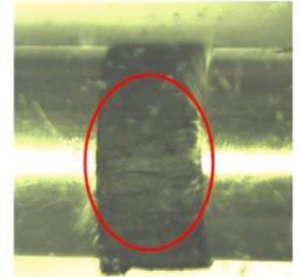

$254 \mu \mathrm{s}$

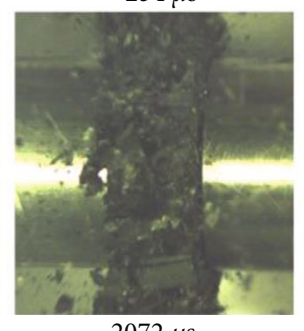

$2072 \mu \mathrm{s}$

(b) $w=5.79 \%$

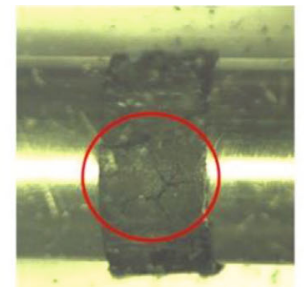

$208 \mu \mathrm{s}$

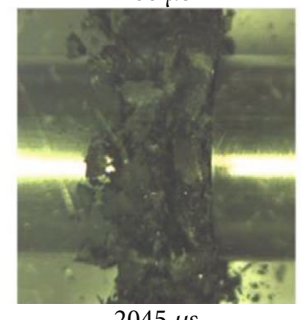

$2045 \mu \mathrm{s}$

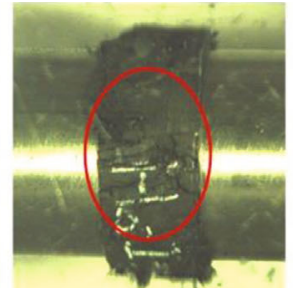

$726 \mu \mathrm{s}$

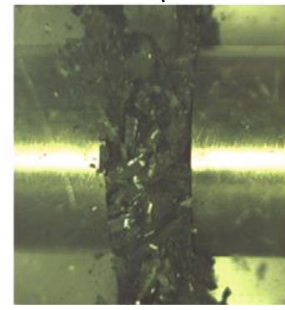

$3090 \mu \mathrm{s}$

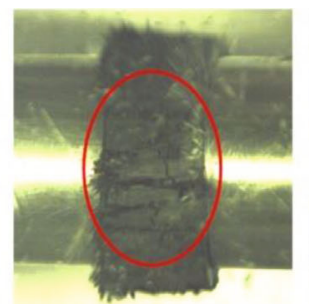

$436 \mu \mathrm{s}$

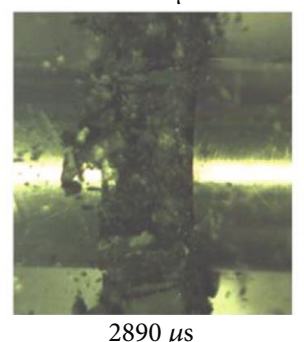

$2890 \mu \mathrm{s}$

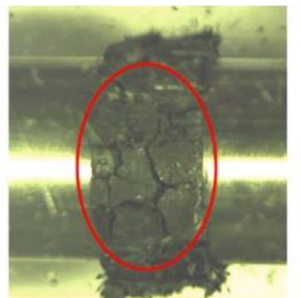

$381 \mu \mathrm{s}$

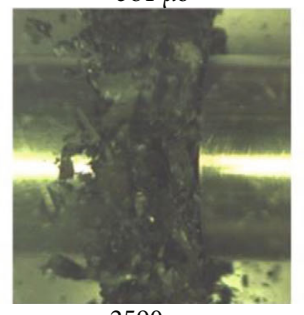

$2590 \mu \mathrm{s}$

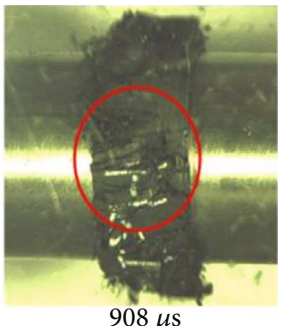

$908 \mu \mathrm{s}$

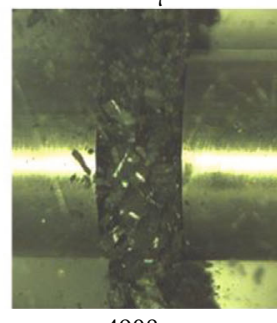

$4908 \mu \mathrm{s}$

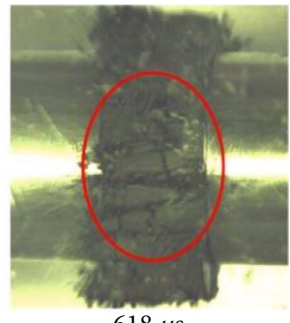

$618 \mu \mathrm{s}$

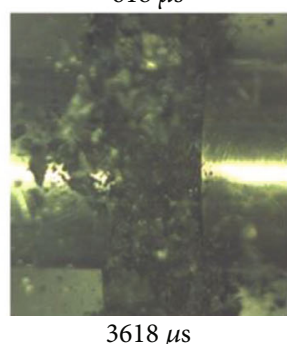

$3618 \mu \mathrm{s}$

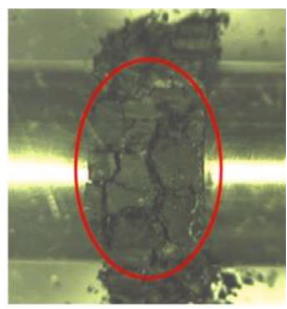

$545 \mu \mathrm{s}$

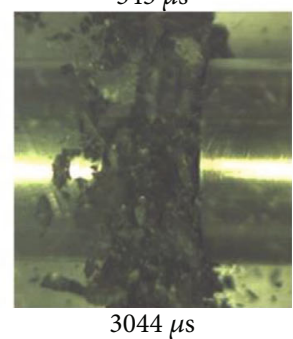

(c) $w=12.53 \%$

FIgURE 10: Dynamic structural damage to water-containing coal samples. 


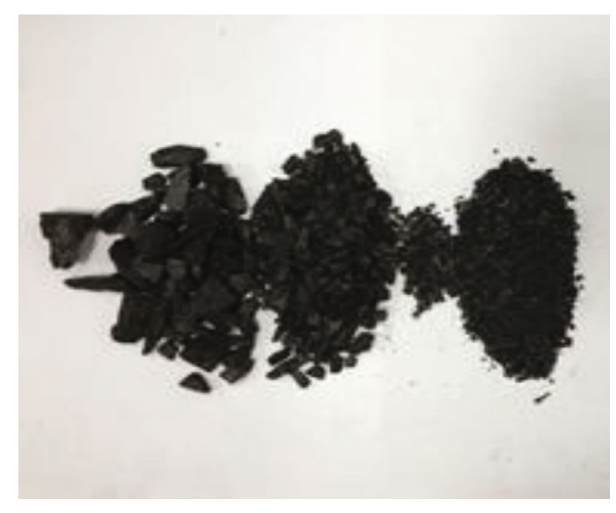

FIgURE 11: Mass of sieved fragments of coal samples.

increases from 2.46 to $3.04,3.52$, and $3.84 \mathrm{GPa}$ (increments of $23.75 \%, 15.75 \%$, and $10.23 \%$, respectively). Finally, for the coal sample with $w=12.53 \%$, the elastic modulus increases from 2.88 to $3.21,3.73$, and $4.22 \mathrm{GPa}$ (increments of $11.46 \%, 16.20 \%$, and $13.14 \%$ ). As with the dynamic compressive strength, the dynamic elastic modulus correlates positively with the strain rate and is logarithmic in strain rate, which shows that an increase in impact load increases the deformation resistance of the coal samples.

3.4. Damage to Coal Samples as a Function of Water Content. Figure 8 shows the dynamic stress-strain curves of coal samples with different water contents. In the fracturecompression stage, the dynamic stress-strain curves fluctuate and grow nonlinearly. The growth in the stress of the coal samples subjected to dynamic loading indeed follows a wave process of stress wave action, which is attributed to the plentiful supply of minerals, impurities, pores, and cracks inside the coal samples. In the early phase of stress-wave propagation, it is difficult for stress and strain to change at the same rate. Additionally, the fracture-compression stage of stressstrain curves of water-containing coal samples is more significant than that of dry coal samples. Consider, for example, the strain rate of 45.92 and $56.38 \mathrm{~s}^{-1}$ : as the water content increases from $0 \%$ to $12.53 \%$, the fracture-compression stage of the coal samples for $\dot{\varepsilon}=45.92 \mathrm{~s}^{-1}$ accounts for $6.46 \%$, $21.25 \%$, and $37.84 \%$ of the curve before the peak. In contrast, the fracture-compression stage of the coal sample for $\dot{\varepsilon}=$ $56.38 \mathrm{~s}^{-1}$ accounts for $11.67 \%, 20.47 \%$, and $19.58 \%$ of the curve before the peak, revealing a negative correlation. As the coal sample absorbs water, the minerals and impurities inside it undergo physical and chemical reactions that soften the samples, giving them remarkable plastic characteristics [42] that increase the time required to compress them.

Figure 9(a) shows the dynamic compressive strength as a function of water content of the coal samples. The scattered distribution of the results means that the dynamic compressive strength of the coal samples with different strain rates reacts differently as water content increases. For instance, as water content increases from $0 \%$ to $12.53 \%$ at a strain rate of $45.92 \mathrm{~s}^{-1}$, the average dynamic compressive strength of the coal samples decreases by $4.04 \%$ and $12.36 \%$, with softening coefficients of 0.96 and 0.84 . At a strain rate of $56.38 \mathrm{~s}^{-1}$, however, the average dynamic compressive strength of the coal samples decreases by $6.85 \%$ and $2.59 \%$, with softening coefficients of 0.93 and 0.91 . In this case, the dynamic compressive strength of the coal samples increases nearly linearly with water content, which is consistent with the result of the relative static load test $[43,44]$. At a strain rate of $68.13 \mathrm{~s}^{-1}$, the dynamic compressive strength of the coal samples increases quadratically with water content. In the immersion hardening of brittle materials such as concrete and sandstone under loading and at a high strain rate, the pore water pressure can intensify to some extent. Since the propagation rate of cracks correlates positively with impact load [45] and a higher strain rate leads to a larger impact load, a higher strain rate leads to faster crack propagation so that the free water in cracks has difficulty reaching the crack tips. In addition, the surface tension along the crack openings hinders crack development [46], which further contributes to limiting the dynamic compressive strength of water-containing media.

Figure 9(b) shows the dynamic elastic modulus of the coal samples as a function of water content. As the water content increases from $0 \%$ to $12.53 \%$, the linear characteristics of dynamic elastic modulus of coal samples are obvious under low strain rate and relatively discrete under high strain rate. Overall, the dynamic elastic modulus of the coal samples is nearly linear in water content, no matter the strain rate, reflecting an improved resistance to deformation of the water-containing coal samples subjected to impact load. Previous findings indicate that the dynamic elastic modulus correlates positively with coal density and stress-wave velocity [47]. Since the coal samples contain numerous large pores and heterogeneous cracks, the pores and cracks absorb stress-wave energy as stress develops in dry coal samples, which attenuates energy during transmission. The pores and cracks in water-containing coal samples are filled with free water, which relieves the structural defects of the coal samples and enhances the density of the coal samples. Also, since the wave velocity in water is much greater than that in air [48], the saturated coal samples have a higher dynamic elastic modulus.

3.5. Dynamic Structural Damage of Water-Containing Coal Samples. A high-speed camera with a frame rate of 110001 frames per second served to monitor the dynamic structural damage of the water-containing coal samples and recorded crack-propagation patterns and impact failures. Taking the loading pressure of $0.1 \mathrm{MPa}$ as an example, the dynamic failure process of water-containing coal samples is shown in Figure 10.

Figure 10(a) shows the dynamic damage failure of a dry coal sample. At $90 \mu \mathrm{s}$, the coal sample undergoes slight axial compression but remains integral. At $545 \mu \mathrm{s}$, several macro parallel cracks appear in the coal sample, indicating uniform dynamic loading of the coal sample. At $726 \mu \mathrm{s}$, the cracks continue to expand and new cracks appear; then, several cracks connect and the coal sample undergoes axial compression and radial swelling. At $908 \mu \mathrm{s}$, the cracks link up with each other, and the coal sample undergoes local failure with a split pattern. The macro deformation becomes more evident, and a small number of coal fragments are ejected. At 
TABle 4: Parameters of the distribution of coal fragments.

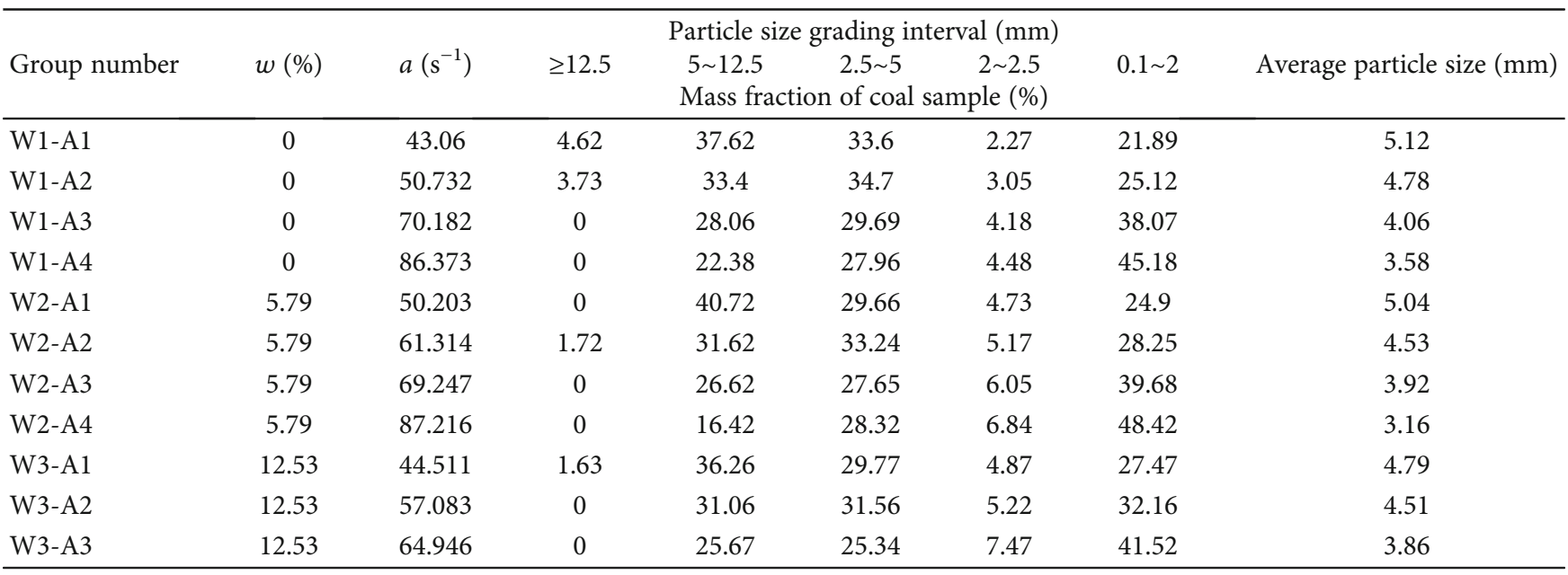

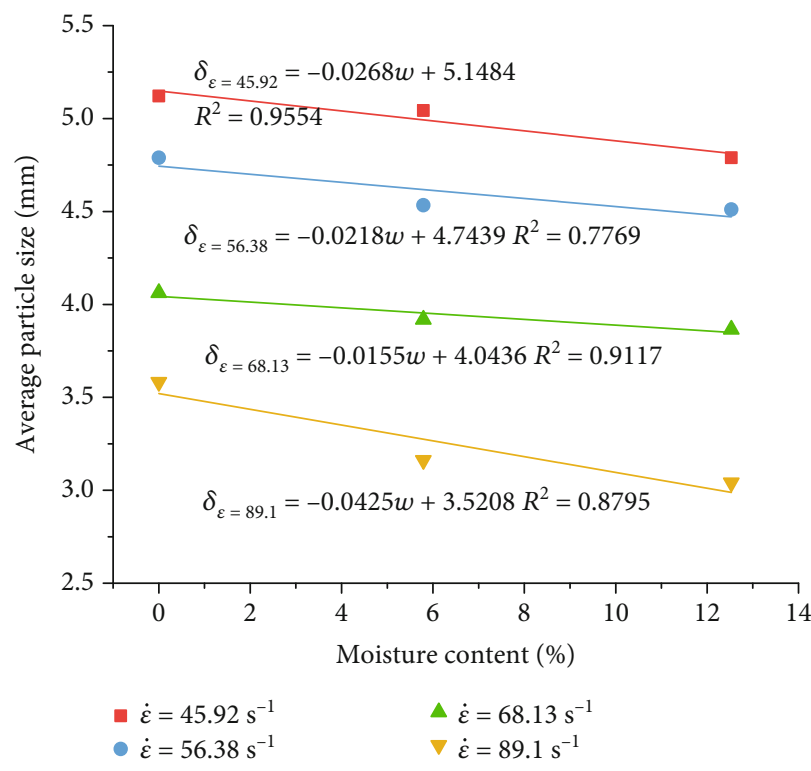

(a) Average particle size vs. water content

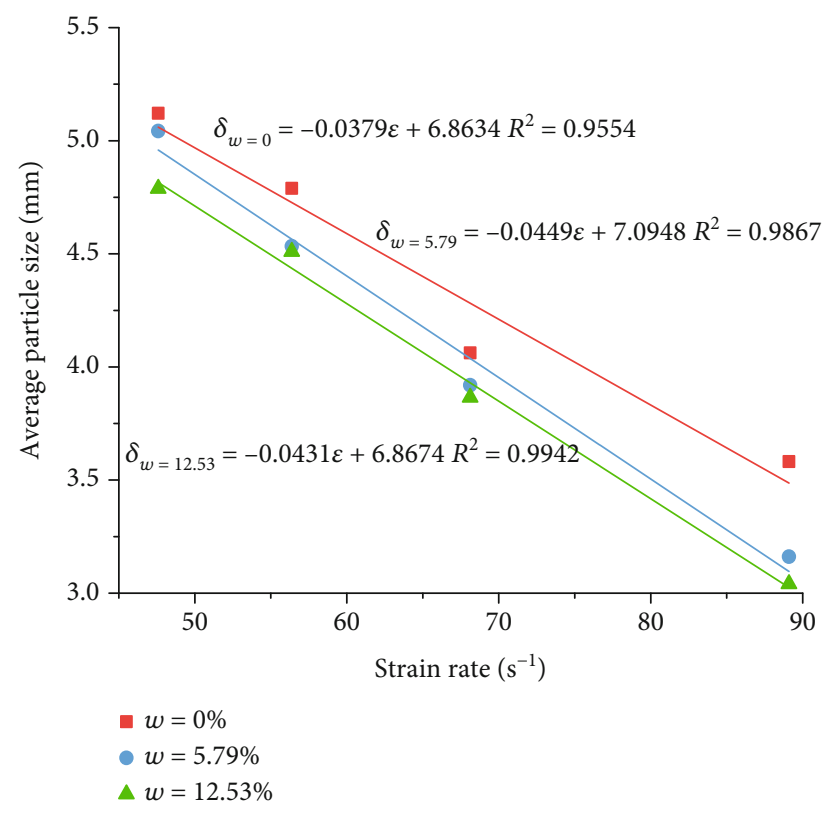

(b) Average particle size vs. strain rate

Figure 12: Average particle size as a function of water content and average particle size as a function of strain rate.

$1272 \mu$ s, the main structure of the coal sample collapses, and the coal sample loses its bearing capacity, causing the ejection of a significant amount of coal fragments. After $2181 \mu \mathrm{s}$, the failure of the coal sample intensifies, leading to the ejection of more coal fragments, which are now smaller in sizes and are ejected a greater distance.

The coal sample with a water content of $5.79 \%$ undergoes a dynamic damage process similar to that of the dry coal sample (see Figure 10(b)), although the time required for crack initialization and the failure of the entire structure is reduced, the coal fragments are smaller, and the damage process is much faster. During the time interval $72-254 \mu \mathrm{s}$, the coal sample undergoes uniaxial compression, parallel cracks appear, and the cracks propagate. During the time interval 436-618 $\mu \mathrm{s}$, crack propagation accelerates, and the cracks begin to connect and link up, which signals the onset of fail- ure of the sample. At $1072 \mu$ s, the main structure undergoes a splitting failure, and the coal fragments are ejected over a small range of distance. After $2072 \mu$ s, the size of the ejected coal fragments decreases, but the ejection distance increases.

Figure 10(c) shows the dynamic-damage failure of coal samples with a water content of $12.53 \%$. At $45 \mu$ s, axial compression of the coal sample begins. At $208 \mu \mathrm{s}$, staggered cracks appear in the middle of the coal sample. At 381-545 $\mu$ s, cracks propagate and gradually connect and link up, with coal fragments being ejected. In addition, the bearing structure of coal samples shows the initial characteristics of crushing. After $990 \mu \mathrm{s}$, the coal samples fracture completely with copious ejection of fragments over a large ejection range.

The macrofailure characteristics of coal samples subjected to dynamic loading essentially reflect the processes in the internal microstructure of the samples [49]. According 
TABLE 5: Parameters of model material.

\begin{tabular}{|c|c|c|c|c|c|c|c|}
\hline Lithology & $\delta(\mathrm{m})$ & $E(\mathrm{GPa})$ & $\mu$ & $\sigma_{\mathrm{t}}(\mathrm{MPa})$ & $C(\mathrm{MPa})$ & $\Phi(\mathrm{deg})$ & $\rho\left(\mathrm{kg} / \mathrm{m}^{3}\right)$ \\
\hline Siltstone & 34 & 1.77 & 0.24 & 0.741 & 5.17 & 34.59 & 2440 \\
\hline Fine sandstone & 8 & 0.81 & 0.21 & 0.518 & 4.38 & 31.84 & 2269 \\
\hline Siltstone & 34 & 2.79 & 0.17 & 0.895 & 5.67 & 36.01 & 2327 \\
\hline Medium-grained sandstone & 6 & 1.40 & 0.18 & 0.487 & 4.25 & 31.35 & 2480 \\
\hline Sandy mudstone & 26 & 2.87 & 0.21 & 1.088 & 6.27 & 37.45 & 2222 \\
\hline Mudstone & 2 & 3.39 & 0.21 & 0.672 & 4.93 & 33.84 & 2428 \\
\hline Coal & 6 & 0.98 & 0.19 & 0.64 & 3.36 & 25.85 & 1387 \\
\hline Mudstone & 6 & 3.52 & 0.19 & 0.686 & 5.81 & 31.78 & 2408 \\
\hline Siltstone & 26 & 2.00 & 0.09 & 0.867 & 6.47 & 33.59 & 2350 \\
\hline Fine sandstone & 16 & 3.15 & 0.15 & 0.51 & 5.11 & 29.49 & 2154 \\
\hline Siltstone & 6 & 4.42 & 0.17 & 0.698 & 5.86 & 31.91 & 2410 \\
\hline Fine sandstone & 20 & 3.00 & 0.17 & 0.923 & 6.67 & 34.07 & 2459 \\
\hline
\end{tabular}

Note: $\delta$ : thickness; $E$ : elastic modulus; $\mu$ : Poisson's ratio; $\sigma_{\mathrm{t}}$ : tensile strength; $C$ : cohesive force; $\Phi$ : angle of internal friction; $\rho$ : density.

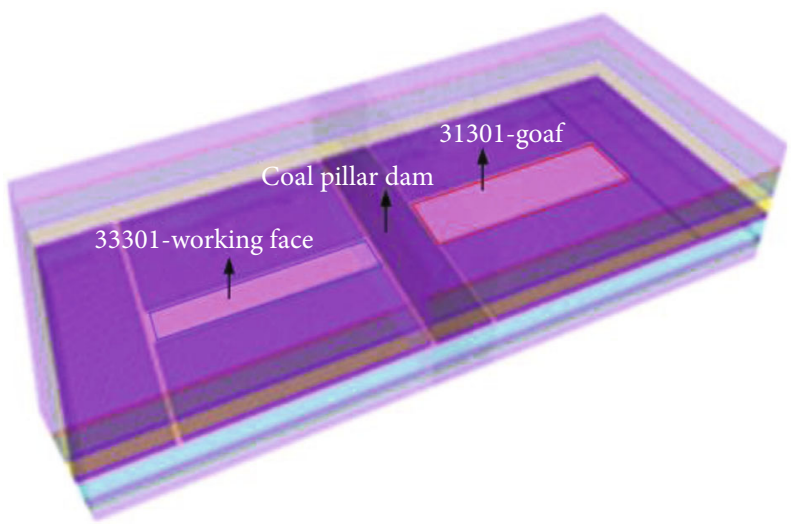

Figure 13: Numerical model schematic diagram.

to fracture mechanics, cracks start to propagate rapidly when the stress-intensity factor at the crack tip exceeds the fracture toughness of the material. Softening due to water erosion of coal samples reduces the cohesion between the internal particles, so the overall strength decreases, which in turn decreases the fracture toughness. Thus, even a small stress can trigger the propagation and failure of cracks, reducing the time to crack propagation and overall failure [50]. As the water content increases further, immersion-induced softening in the coal samples significantly reduces their fracture toughness, and when the stress intensity factor achieves the critical value, more cracks propagate simultaneously, manifesting macroscopic staggered cracks.

3.6. Characteristics of Fragments of Water-Containing Coal Samples. To further quantify how water content and strain rate affect the structural damage of coal samples, fragments of coal samples were collected after the impact tests and sieved through mesh sieves with opening sizes of 12.5, 5.0, $2.5,2.0$, and $0.1 \mathrm{~mm}$. The mass of particles retained from each sieve is shown in Figure 11.

The median fragment size for a given sieve is called the average particle size, and the accumulated mass by percentage for each sieve multiplied by the corresponding average particle size gives the average particle size of the failed coal sample. Thus,

$$
\delta=\sum_{1}^{i} \eta_{i} \bar{d}_{i}
$$

where $\delta$ is the average particle size of the failed coal sample $(\mathrm{mm}), \eta_{i}$ is the percent of the total mass in grading interval $i, \bar{d}_{i}$ is the average particle size in grading interval $i(\mathrm{~mm})$, and $i=1-5$ labels the sieve gradings. Table 4 lists the characteristic parameters of the coal fragments for the various water contents and strain rates.

Figure 12(a) shows the average fragment size as a function of water content. The average size of a coal fragment decreases as water content increases, suggesting that increasing water content significantly perturbs the coal sample. The slope of the curve has an absolute value of 0.0425 at $\varepsilon=$ $89.1 \mathrm{~s}^{-1}$, which is significantly greater than the slope at $\varepsilon=$ $45.92-68.13 \mathrm{~s}^{-1}$, which means that a high-impact load causes a more severe failure compared with that under low impacts. Since the entire water-containing coal sample is softened, particles are more likely to separate as cohesion between them decreases, so a high-impact load may generate more coal fragments of small size. The average size of coal fragments as a function of strain rate (see Figure 12(b)), which approaches a negative linear correlation and an increase in impact load, also intensifies the failure of the coal sample. The slope of the fit should reflect the sensitivity of the coal sample to strain rate: the results $k_{w=0}=-0.0379, k_{w=5.79}$ $=-0.0449$, and $k_{w=0}=-0.0431$ indicate that the strain rate has a greater effect on particle size in water-containing coal samples than in dry coal samples. Thus, both water content and strain rate should exacerbate the failure of the coal samples, and both should promote each other.

\section{Numerical Simulation}

4.1. Project Background and Numerical Model. As a key part of underground reservoirs, coal-pillar dams form the 


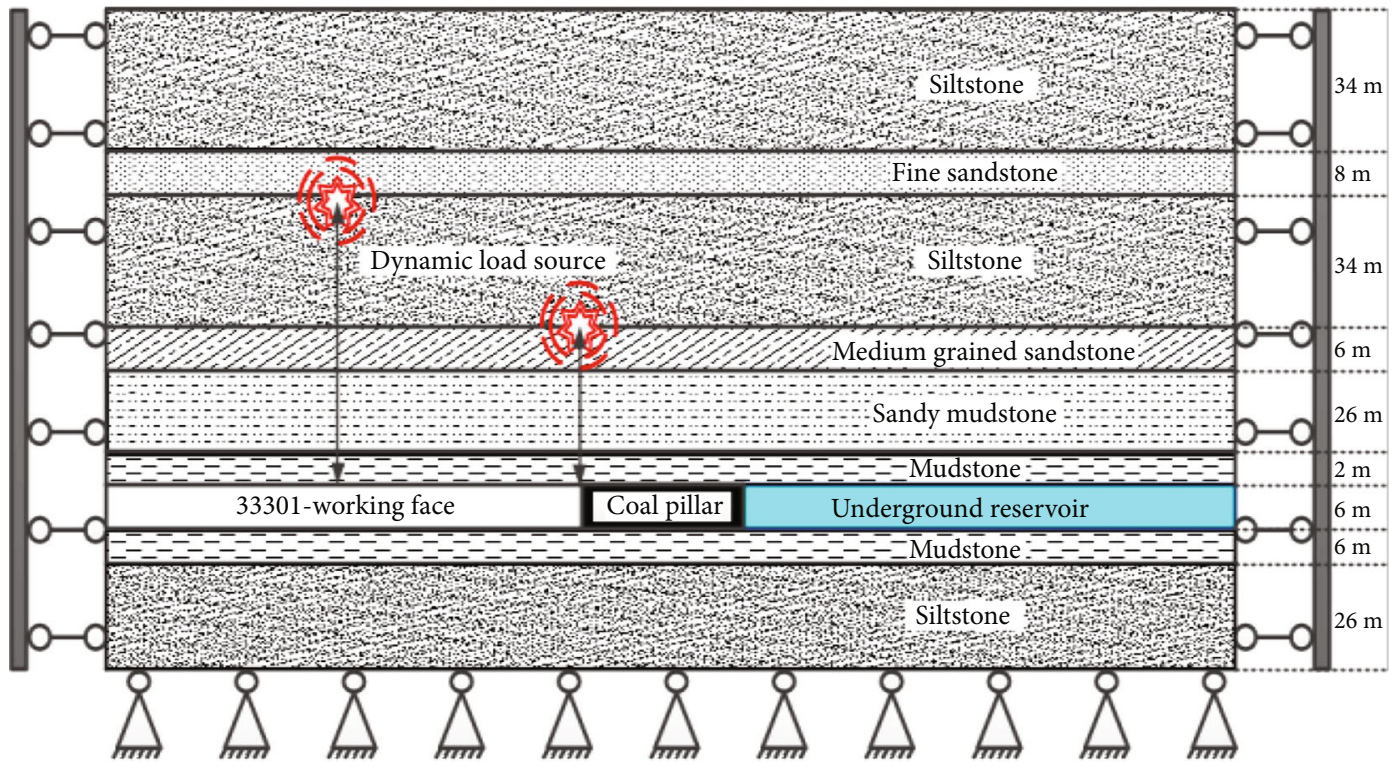

FIgURE 14: Location of dynamic load in the model.

protective coal pillars set by the workface. The disturbance caused by mining activities in contiguous workfaces includes mining-induced static load on the coal-pillar dam and minetremor-induced dynamic loading such as caused by roof fracturing or fault slips. An excessive advance speed of the workface can also lead to large areas of suspended roof, stress concentration areas in the roof, and a large accumulation of elastic energy [51, 52]. When a roof fractures and slips, the rapid release of elastic energy produces violent shocks that lead to dynamic loads $[53,54]$ and shock waves that emanate from the source and are transmitted through the rock, also resulting in dynamic loading of the coal-pillar dam [55]. In light of this analysis, we numerically simulated a coal-pillar dam subject to dynamic loading by using the finitedifference software FLAC3D. The simulation is used to analyze the stress distribution and damage characteristics of the coal-pillar dam.

The underground reservoir of Goaf 31301 in the Chahasu coal mine in western China is used as the simulation object. The workface is nearly horizontal 3-1 coal with an average thickness of $5.87 \mathrm{~m}$, and the immediate roof and floor consist of sandy mudstone. The underground reservoir of Goaf 31301 is close to Workface 33301, with protecting coal pillars $74 \mathrm{~m}$ in length for the coal-pillar dam of the reservoir. Mining is done on Workface 33301.

In light of the location of the two workface planes and the geological conditions, the model of the coal seam is $6 \mathrm{~m}$ thick and has a size of $914 \times 400 \times 190 \mathrm{~m}^{3}$ (length $\times$ width $\times$ height), and the four boundaries and the bottom end are constrained. A uniform load with a magnitude of $6.88 \mathrm{MPa}$ is applied to the top of the coal seam to model the overburden weight $300 \mathrm{~m}$ above, and boundary pillars along the $X$ and $Y$ axes are set as 108 and $150 \mathrm{~m}$ long. The Mohr-Coulomb model is used to model the material with the parameters given in Table 5. Figure 13 shows the numerical model. Based on the mining practice used at Workface 33301, the excavation in each step is $10 \mathrm{~m}$ to reflect the real advance speed of
$10 \mathrm{~m} / \mathrm{d}$ of the workface. And then the mining of the workface is simulated [56].

Since dynamic load is usually induced by mining when the coal is in the limit of static balance, static stress balance is a prerequisite for simulating dynamic load. To simulate the period from the beginning of excavation until static stress balance in Workface 33301, we used the built-in dynamic module in FLAC3D, and shaking focuses were imposed at various locations in the coal roof. Given the existence of low-strength mudstone and sandy mudstone within $28 \mathrm{~m}$ of the immediate roof, the $34 \mathrm{~m}$ long medium-grained sandstone and the $76 \mathrm{~m}$ long fine sandstone in the roof are assumed to fracture during the advance of the adjacent workface, and a shaking focus is applied in each layer. Both the near and far fields are considered in the analysis of the disturbance to the coal-pillar dam caused by high dynamic loading. Based on previous findings [56, 57], the magnitude of the dynamic load was determined to be $50 \mathrm{MPa}$. The focus produces vertical and horizontal components at the same time, the dynamic load waveform is described by a sinusoidal wave, the bottom of the model is a viscous boundary, the four sides of the model are free-field boundaries, and local damping is applied. The frequency of the shock wave is $50 \mathrm{~Hz}$, dynamic loading lasts for one period, and the simulation time is $0.2 \mathrm{~s}$. Figure 14 shows where the dynamic load is applied.

4.2. Stress Distribution in Coal-Pillar Dam. During simulation, the effects of dynamic load disturbance on the vertical stress of the coal-pillar dam were maximized within the 600 time steps. As a result, vertical stress distributions of the longitudinal section of the coal-pillar dam within 600 time steps were involved in simulation (see Figure 15). When a mine tremor is excited in the far field (e.g., in the overburden rock), shock waves emanate elliptically and energy is attenuated as it travels further from the source. The arrival of the shock waves at the coal-pillar dam changes the vertical stress, eventually concentrating stress on both sides of the dam. The 

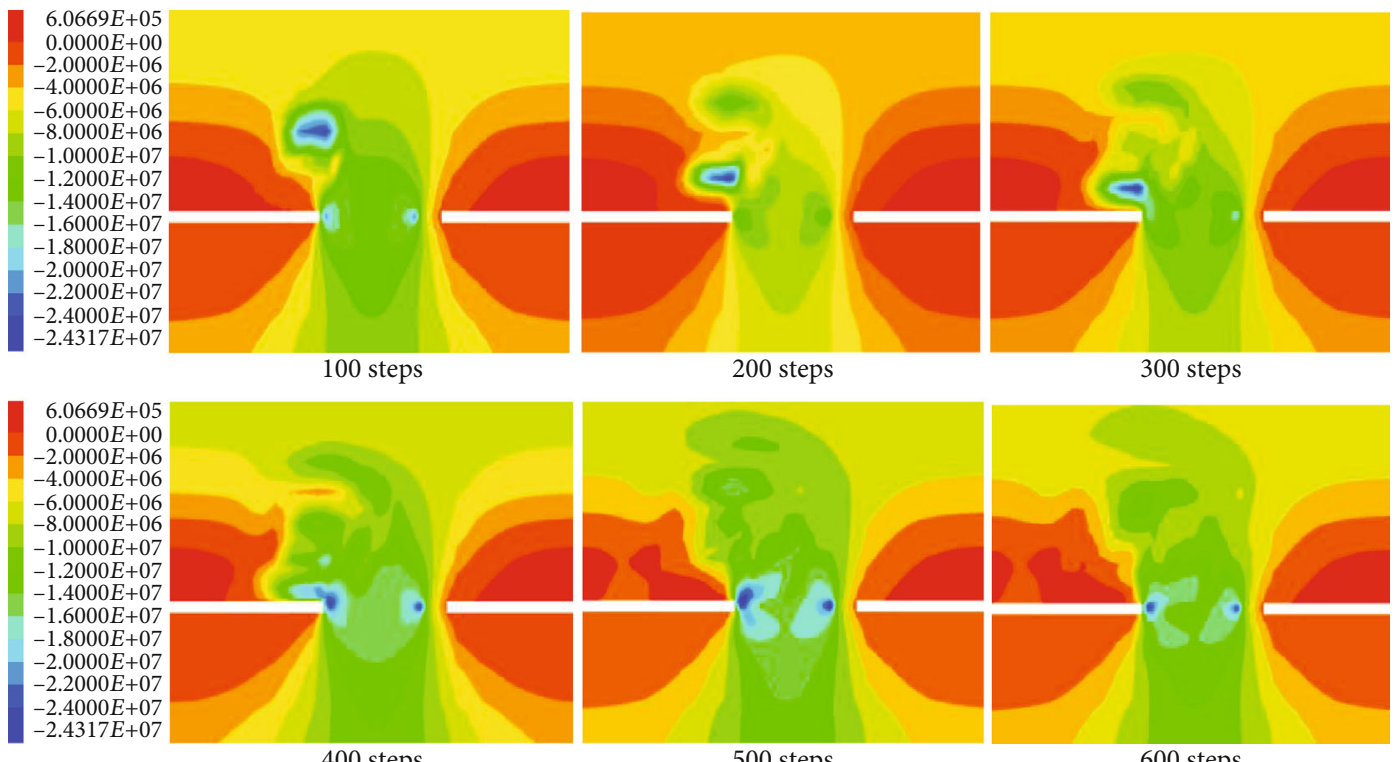

(a) Near-field mine tremor disturbance

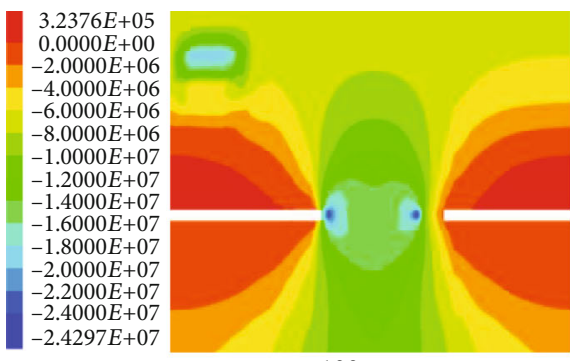

100 steps

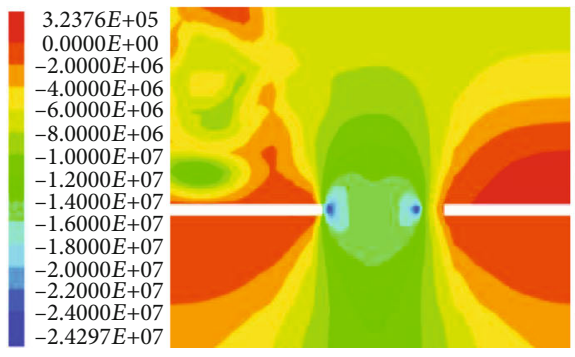

400 steps

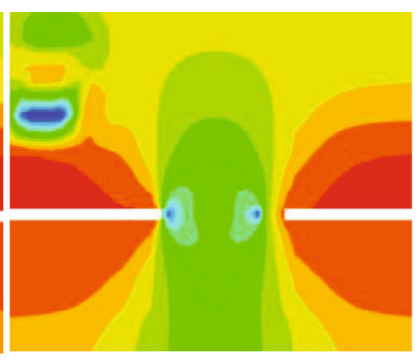

200 steps

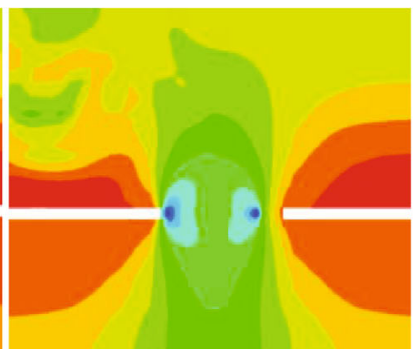

500 steps

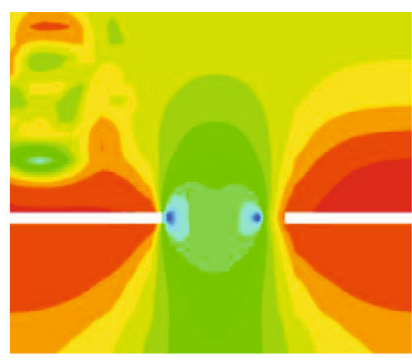

300 steps

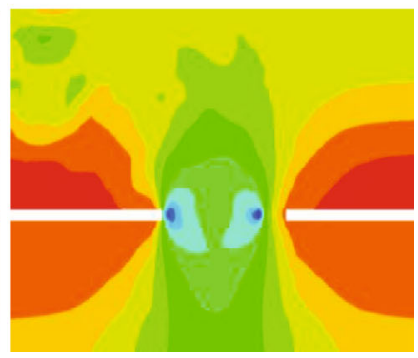

600 steps

(b) Far-field mine tremor disturbance

FIgURE 15: Vertical stress as a function of time in near and far fields due to disturbance by dynamic loading.

transmission of mine tremors in the near field is similar to that of shock waves in the far field, but the shock waves propagate farther in the far field and the energy is more strongly attenuated, reducing the disturbance to the coal-pillar dam. Additionally, the coal-pillar dam on the mining side experiences a greater change in stress as it is closer to the shockwave source, and dynamic loading results in greater stress and a larger stress-concentration area. Conversely, the coalpillar dam on the reservoir side experienced less serious dynamic loading disturbances. The stress distribution is similar in both near field and far field.

Figure 16 shows the vertical stress distribution in the coalpillar dam. With dynamic loading, the stress-concentration areas at both ends of the coal-pillar dam expand significantly and gradually extend toward the floor and the elastic zone in the middle of the coal pillar, and the peak stress also increases slightly. Compared with mine tremors in the far field, nearfield mine tremors more severely disturb the coal-pillar dam and widen the stress-concentration area, and a large range of damage failure is likely to occur in real situations. Additionally, the distribution of the elastic zone differs from that under the static load balance after mining, and a high-stress area expands from a heart shape in static equilibrium to an elliptical shape, while gradually extending to the roof and floor.

To further quantify the dynamic disturbance of the vertical stress in the coal-pillar dam and to observe vertical stress, we select measuring points in peak stress areas at both ends of the coal-pillar dam and in the middle elastic zone, as 


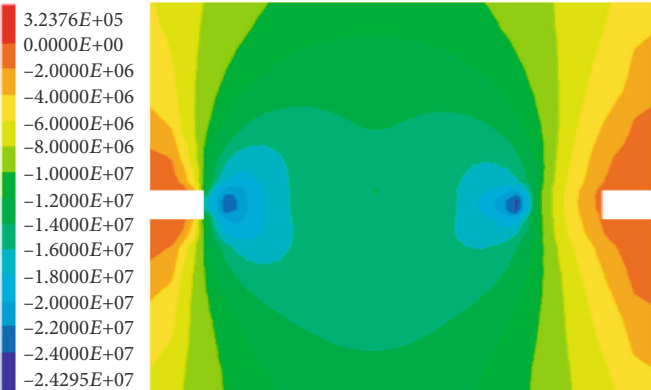

(a) Stress equilibrium state after mining

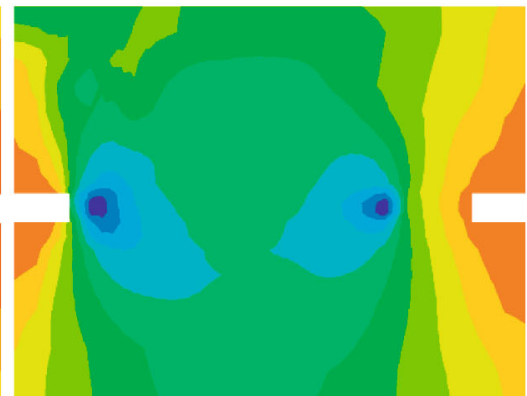

(b) Near-field mine tremor disturbance

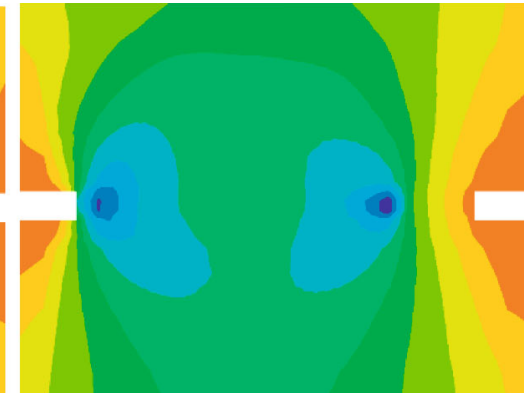

(c) Far-field mine tremor disturbance

FIgURE 16: Vertical stress distribution in coal-pillar dam before and after dynamic loading.

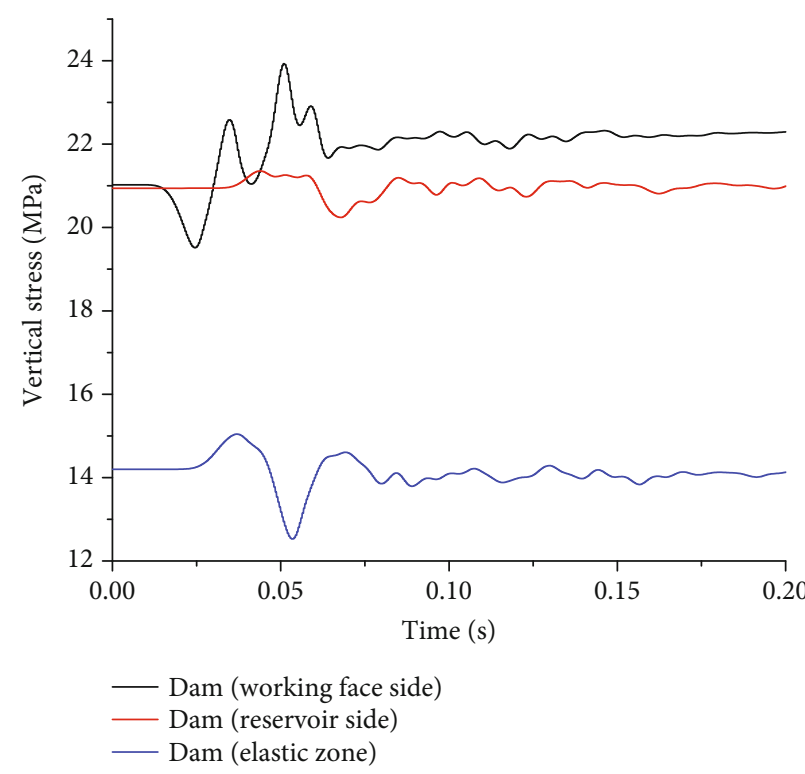

(a) Near field

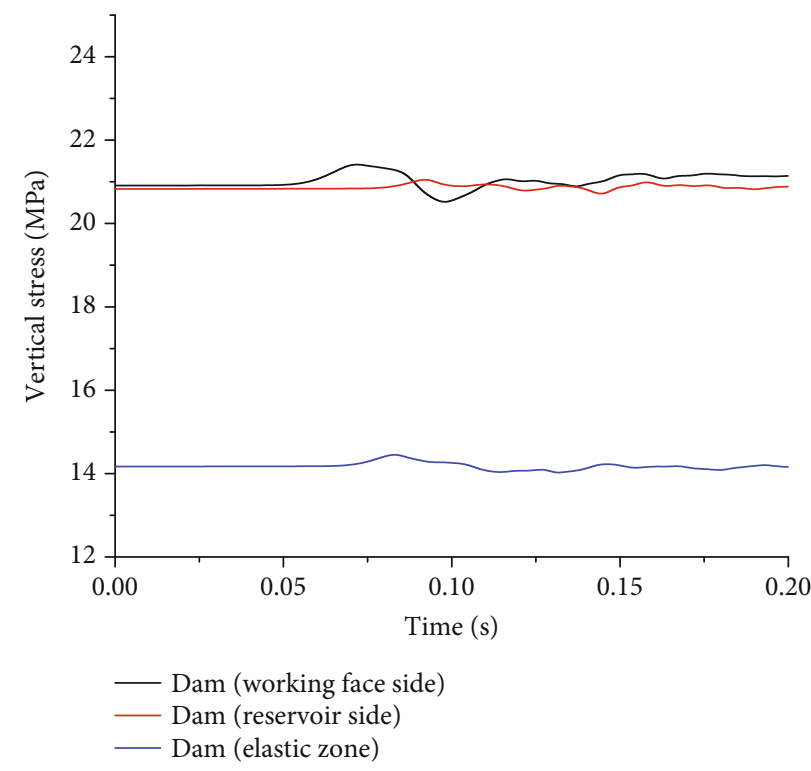

(b) Far field

FIGURE 17: Vertical stress of coal-pillar dam subjected to dynamic loading.

shown in Figure 17. A mine tremor causes dynamic loading in the near field, with an increase in peak stress of $4.6 \mathrm{MPa}$ at the coal-pillar dam on the mining side, an increase of 2.7 $\mathrm{MPa}$ in the elastic zone, and an increase of $0.9 \mathrm{MPa}$ at the coal-pillar dam on the reservoir side. A mine tremor causes dynamic loading in the far field, and peak stress increases by $0.9 \mathrm{MPa}$ at the coal-pillar dam on the mining side, by $0.5 \mathrm{MPa}$ in the elastic zone, and by $0.2 \mathrm{MPa}$ at the coalpillar dam on the reservoir side. These results show that the coal-pillar dam experiences the largest change in vertical stress and that the disturbance caused by dynamic loading in the far field is more serious than that in the near field. Additionally, the coal-pillar dam on the mining side and elastic zone of the coal-pillar dam face the waves, which amplifies the change in stress more vis-à-vis the reservoir side. Since the coal-pillar dam on the mining side is closest to the shock-wave source, it experiences the most severe disturbance, while the stress mutation occurs first, and the peak stress is also the highest after the end of dynamic load. In engineering practice, under the duplicating effect of overburden stress and mine tremors caused by dynamic loading, the coal-pillar dam may be damaged and fail if its stress exceeds the ultimate strength of coal, whereas the coal-pillar dam on the reservoir side becomes more vulnerable due to softening caused by immersion in water.

4.3. Damage to Coal-Pillar Dam. Figure 18 shows the extent of the plastic zone in the coal-pillar dam before and after mine-tremor-induced dynamic loading. The stress field reaches static equilibrium after the advancement of the two workfaces, and plastic zones develop on both sides of the coal-pillar dam, with the deepest plastic zone at the coalpillar dam on the mining side being $6 \mathrm{~m}$. Nevertheless, the seepage in the coal-pillar dam on the reservoir side widens the range of the plastic zone, and local failure extends as far as $24 \mathrm{~m}$ deep. Near-field mine-tremor-induced dynamic loading enlarges the plastic zones on both sides of the coalpillar dam to 12 and $26 \mathrm{~m}$, and the range also extends in the direction in which Workface 33301 advances. Far-field mine-tremor-induced dynamic loading followed by the long-distance transmission and rapid energy attenuation causes no obvious change in the depth of the plastic zones 


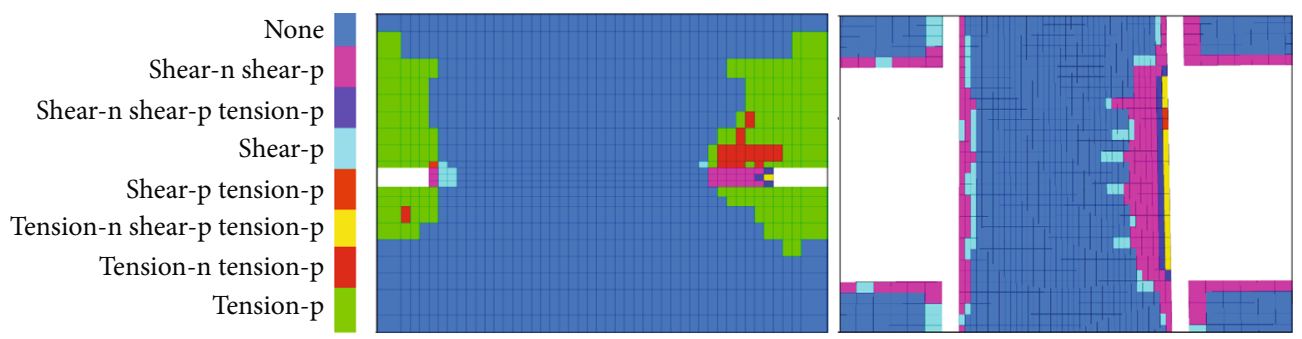

(a) Stress equilibrium state after mining

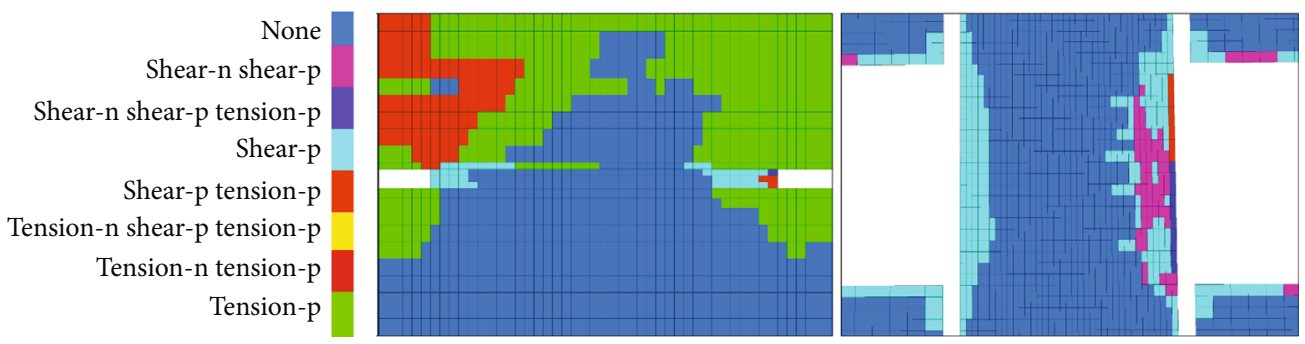

(b) Near-field mine tremor disturbance

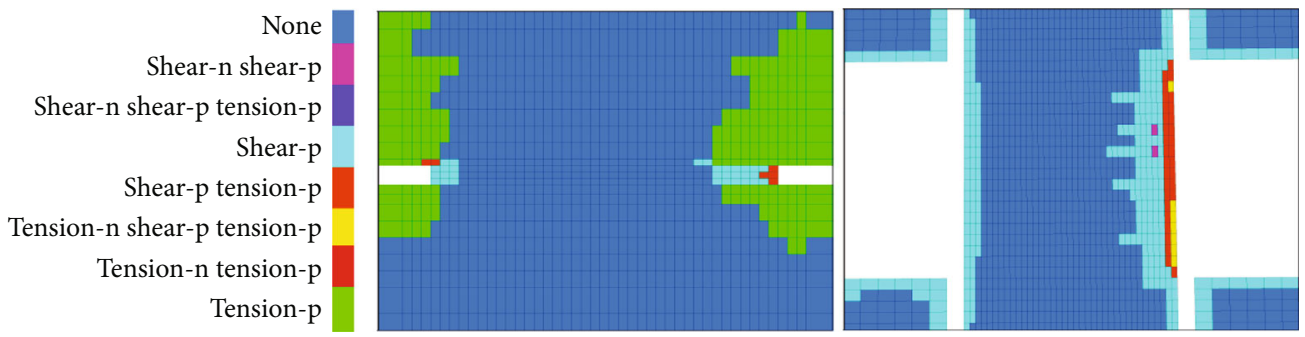

(c) Far-field mine tremor disturbance

FIGURE 18: Extent of plastic zone in coal-pillar dam before and after dynamic loading.

on both sides of the coal-pillar dam, whereas the range extends slightly in the direction in which the workface advances. Since the coal-pillar dam on the mining side faces the coming shock waves, it experiences the most damage and the most severe disturbance due to dynamic loading in both the near and far fields. Overall, high-intensity dynamic loading increases the damage in coal-pillar dams, and due to the impact of long-term static loading, the plastic zone is also further broadened. These conditions are likely to provoke an incident once the disturbance reaches the reservoir.

\section{Conclusions}

Throughout the whole paper, several key conclusions are obtained.

The water content of a coal sample is well described by a logarithmic function of immersion time, and the curve may be divided into three stages based on its slope: (I) a rapidly increasing stage (0-5 h), (II) a slowly increasing stage (5-16 $\mathrm{h}$ ), and (III) a near-saturation stage (16-32 h). Based on these results, we use in this study coal samples with water contents of $0.00 \%, 5.79 \%$, and $12.53 \%$.

The mechanical performance of coal samples depends on the strain rate and water content. At low strain rate and high water content, the compression stage accounts for a large fraction of the stress-strain curve, whereas the elastic stage accounts for a relatively small fraction of the stress-strain curve. The dynamic compressive strength and elastic modulus of the coal samples are exponential and logarithmic functions of strain rate, respectively, and have a strong positive correlation. As the water content increases, the dynamic elastic modulus of the coal sample increases nearly linearly while the dynamic compressive strength decreases. In addition, the effect of strain rate on the mechanical performance of the coal samples counters that of water content. As the strain rate increases to $89.1 \mathrm{~s}^{-1}$, the compressive strength first decreases, before increasing with water content.

Water content and strain rate are two factors that affect the dynamic failure of coal samples. For coal samples subjected to a given impact load, an increase in water content shortens the time for crack initiation and failure and intensifies the failure, and parallel cracks become staggered cracks as they propagate. The average size of coal fragments reduces with increasing water content and strain rate, which tends to amplify the effect of each. A high water content and a large strain rate can minimize the average size of coal fragments.

Numerical simulations of the coal-pillar dam exposed to mine-tremor-induced dynamic loading provide guidance for engineering practice. Shock waves emanate in an elliptical pattern once the dynamic loading is initiated in the near or far field, thereby concentrating the stress on both sides of the coal-pillar dam and expanding the high-stress area as well as the plastic zone. A much greater disturbance occurs in the near field. Since the workface of the coal-pillar dam faces the 
coming shock waves, both the peak stress and the range of the plastic zone increase more than in the middle part of the coal-pillar dam and on the reservoir side, exacerbating damage to the project.

\section{Data Availability}

The data used to support the findings of this study are available from the first author or corresponding author upon request.

\section{Conflicts of Interest}

The authors declare that there is no conflict of interest regarding the publication of this paper.

\section{Authors' Contributions}

All authors have agreed to the listing of authors.

\section{Acknowledgments}

This research was funded by the "National Natural Science Foundation of China," grant number 51874283.

\section{References}

[1] C. J. Tang, Q. L. Yao, Z. Y. Li, Y. Zhang, and M. Ju, "Experimental study of shear failure and crack propagation in waterbearing coal samples," Energy Science \& Engineering, vol. 7, no. 5, pp. 2193-2204, 2019.

[2] National Bureau of statistics of the People's Republic of China, Energy Production in December 2020, p. 12, 2020, http://www .stats.gov.cn/tjsj/zxfb/202101/t20210118_1812426.html.

[3] D. Z. Gu, "Theory framework and technological system of coal mine underground reservoir," Journal of China Coal Society, vol. 40, no. 2, pp. 239-246, 2015.

[4] D. Z. Gu, Y. Zhang, and Z. G. Cao, "Technical progress of water resource protection and utilization by coal mining in China," Coal Science and Technology, vol. 44, no. 1, pp. 1-7, 2016.

[5] J. Fang, Q. L. Yao, W. N. Wang, C. J. Tang, and G. Wang, "Experimental study on damage characteristics of siltstone under wateraction," Journal of China Coal Society, vol. 43, pp. 412-419, 2018.

[6] L. H. Xu, S. M. Liu, and Y. Q. Li, "Experimental studies on rock softening properties in Danjiangkou Reservoir area," Rock and Soil Mechanics, vol. 5, pp. 1430-1434, 2008.

[7] Q. L. Yao, X. H. Li, J. Zhou, M. Ju, Z. Chong, and B. Zhao, "Experimental study of strength characteristics of coal specimens after water intrusion," Arabian Journal of Geosciences, vol. 8, no. 9, pp. 6779-6789, 2015.

[8] N. Li, H. Xu, and B. Hu, "Shear creep characteristics of sandstone under dry and saturated states," Rock and Soil Mechanics, vol. 2, pp. 439-443, 2012.

[9] E. Verstrynge, R. Adriaens, J. Elsen, and K. van Balen, "Multiscale analysis on the influence of moisture on the mechanical behavior of ferruginous sandstone," Construction and Building Materials, vol. 54, pp. 78-90, 2014.

[10] J. Zhu, J. Deng, Y. Huang, and Z. He, "Influence of water on the fracture process of marble with acoustic emission monitor- ing," KSCE Journal of Civil Engineering, vol. 23, no. 7, pp. 3239-3249, 2019.

[11] B. Vásárhelyi, "Statistical analysis of the influence of water content on the strength of the miocene limestone," Rock Mechanics and Rock Engineering, vol. 38, no. 1, pp. 69-76, 2005.

[12] D. Li, L. N. Y. Wong, G. Liu, and X. Zhang, "Influence of water content and anisotropy on the strength and deformability of low porosity meta-sedimentary rocks under triaxial compression," Engineering Geology, vol. 126, pp. 46-66, 2012.

[13] W. J. Yang, W. Wang, D. Y. Li, J. Wang, and W. C. Liu, "Experimental study on mechanical characteristics of coal samples in natural and forced saturation state," Journal of Safety Science and Technology, vol. 13, no. 11, pp. 129-134, 2017.

[14] Q. L. Yao, T. Chen, M. H. Ju, S. Liang, Y. Liu, and X. Li, "Effects of water intrusion on mechanical properties of and crack propagation in coal," Rock Mechanics and Rock Engineering, vol. 49, no. 12, pp. 1-11, 2016.

[15] Q. L. Yao, Researches on Strength Weakening Mechanism and Control of Water-Enriched Roofs of Roadway, Dissertation, China University of Mining and Technology, 2011.

[16] D. Xia, T. H. Yang, T. Xu, P. Wang, and Y. Zhao, "Experimental study on AE properties during the damage process of water-saturated rock specimensbased on time effect," Journal of China Coal Society, vol. 40, pp. 337-345, 2015.

[17] D. Z. Gu, Y. G. Yan, Y. Zhang, E. Z. Wang, and Z. G. Cao, "Experimental study and numerical simulation for dynamic response of coal pillars in coal mine underground reservoir," Journal of China Coal Society, vol. 41, no. 7, pp. 1589-1597, 2016.

[18] P. Yuan and R. Q. Ma, "Split Hopkinson pressure bar tests and analysis of coalmine sandstone with various moisture contents," Chinese Journal of Rock Mechanics and Engineering, vol. 34, pp. 2888-2893, 2015.

[19] L. M. Dou, C. P. Lu, Z. L. Mu, X. T. Zhang, and Z. H. Li, "Rock burst tendency of coal-rock combinations sample," Journal of Mining \& Safety Engineering, vol. 22, no. 1, pp. 43-46, 2006.

[20] C. Y. Liang, X. Li, S. D. Li, J. M. He, and C. F. Ma, "Study of strain rates threshold value between static loading and quasidynamic loading of rock," Chinese Journal of Rock Mechanics and Engineering, vol. 31, no. 6, pp. 1156-1161, 2012.

[21] L. X. Huang, "Development and new achievements of rock dynamics in China," Rock and Soil Mechanics, vol. 32, no. 10, pp. 2889-2900, 2011.

[22] S. H. Wang, X. D. Zhang, M. Chen, F. L. Wang, and Y. S. Cai, "Application of SHPB system in rock mechanics experiment teaching and exploration of curriculum reform," Experimental Technology and Management, vol. 37, no. 2, pp. 182-185, 2020.

[23] W. Wang, Experimenta Study on the Mechanical Response of Water-Saturated Coal Samples under Coupled StaticDynamic Loading, Dissertation, Henan Polytechnic University, 2016.

[24] Z. Ya and S. Zeng, "Strain rate effect analysis of rock based on SHPB test," GOLD, vol. 40, no. 6, pp. 40-42, 2019.

[25] G. M. Zhao, W. W. Ma, and X. R. Meng, "Damage modes and energy characteristics of rock-like materials under dynamic load," Rock and Soil Mechanics, vol. 36, no. 12, pp. 35983605, 2015.

[26] R. L. Shan, R. Q. Cheng, and W. J. Gao, "Study on dynamic constitutive model of anthracite of yunjialing coal mine," 
Chinese Journal of Rock Mechanics and Engineering, vol. 25, no. 11, pp. 2258-2263, 2006.

[27] H. Zhang, J. H. Zhang, and L. P. Dai, "Experimental study on correlation between strength and failure mode of rock subjected to external loads," Journal of Liaoning Technical University (Natural Science), vol. 37, no. 5, pp. 776-781, 2018.

[28] M. Friedman, R. D. Perkins, and S. J. Green, "Observation of brittle-deformation features at the maximum stress of westerly granite and solenhofen limestone," International Journal of Rock Mechanics and Mining, vol. 7, no. 3, pp. 297-302, 1970.

[29] F. Jiang, Z. M. Li, N. C. Wang, H. Guo, and X. Xu, "Research on dynamic characteristics of Shanxi black granite under high strain rates," Journal of Vibration and Shock, vol. 35, no. 8, pp. 177-182, 2016.

[30] Y. K. Fu, B. J. Xie, and Q. F. Wang, "Dynamic mechanical constitutive model of the coal," Journal of China Coal Society, vol. 38, no. 10, pp. 1769-1774, 2013.

[31] X. H. Liu, R. Zhang, and J. F. Liu, "Dynamic test study of coal rock under different strain rates," Journal of China Coal Society, vol. 37, no. 9, pp. 1528-1534, 2012.

[32] S. Demirdag, K. Tufekci, R. Kayacan, H. Yavuz, and R. Altindag, "Dynamic mechanical behavior of some carbonate rocks," International Journal of Rock Mechanics and Mining Sciences, vol. 47, no. 2, 2009.

[33] J. Muralha, "ISRM suggested method for laboratory determination of the shear strength of rock joints: revised version," Rock Mechanics and Rock Engineering, vol. 47, no. 1, pp. 291-302, 2014.

[34] The National Standard Compilation Groups of PRC, GB/T23561.7-2009 Methods for Determining the Physical and Mechanical Properties of Coal and Rock, Standards Press of China, Beijing, 2009.

[35] Ministry of Land and Resources of the PRC, Regulation for Testing the Physical and Mechanical Properties of Rock, Standards Press of China, Beijing, 2015.

[36] L. Q. Yu, Q. L. Yao, X. H. Li, W. Wang, H. Han, and M. Zhang, "Experimental study of failure characteristics and fissure propagation in hydrous siltstone," Arabian Journal of Geosciences, vol. 13, no. 13, 2020.

[37] L. F. Rong, C. M. Mu, and W. Q. Zhang, "Mechanical properties and establishment of constitutive relation of coal rock in 13-1 coal seam from Panxie coalfield under impact load," Journal of China Coal Society, vol. 40, no. S1, pp. 40-46, 2015.

[38] E. Hoek and Z. T. Bienawski, "Brittle fracture propagation in rock under compression," International Journal of Fracture Mechanics, vol. 1, pp. 137-155, 1965.

[39] E. Eberhardt, D. Stead, B. Stimpson, and R. S. Read, "Identifying crack initiation and propagation thresholds in brittle rock," Canadian Geotechnical Journal, vol. 35, no. 2, pp. 222-233, 1998.

[40] Q. Ping, M. J. Wu, P. Yuan, and H. Zhang, "Experimental study on dynamic mechanical properties of high temperature sandstone under impact loads," Chinese Journal of Rock Mechanics and Engineering, vol. 38, no. 4, pp. 782-792, 2019.

[41] M. Li, X. B. Mao, L. L. Cao, M. A. O. Rong-Rong, and P. U. Hai, "Experimental study on mechanical properties of coal under high strain rate," Journal of Mining and Safety Engineering, vol. 32, no. 2, pp. 317-324, 2015.

[42] K. F. Hu, Q. Feng, and X. T. Wang, "Experimental research on mechanical property of phyllite tunnel surrounding rock under different moisture state," Geotechnical and Geological Engineering, vol. 35, no. 1, pp. 303-311, 2017.

[43] Z. L. Zhou, C. Xin, W. Z. Cao, X. Li, and C. Xiong, "Influence of water content on mechanical properties of rock in both saturation and drying processes," Rock Mechanics and Rock Engineering, vol. 49, no. 8, pp. 3009-3025, 2016.

[44] M. R. Vergara and T. Triantafyllidis, "Influence of water content on the mechanical properties of an argillaceous swelling rock," Rock Mechanics and Rock Engineering, vol. 49, no. 7, pp. 2555-2568, 2016.

[45] X. Y. Wang, Z. M. Zhu, H. Qiu, D. Y. Wan, F. Wang, and M. Wang, "Study of the effect of stratifications on crack propagation behaviors in shale under impacting loads," Chinese Journal of Rock Mechanics and Engineering, vol. 38, no. 8, pp. 1542-1556, 2019.

[46] H. L. Wang and Q. B. Li, "Micromechanics mechanism of variation of static and dynamic compressive strength of saturated concrete," Shuili Xuebao, vol. 50, no. 8, pp. 958-962, 2006.

[47] B. T. Xu, J. M. Yi, and Y. X. Wang, "Characteristics and engineering significance of dynamic and static elastic modes under dry and wet state of rock," Chinese Journal of Rock Mechanics and Engineering, vol. 19, no. S1, pp. 1755-1757, 2001.

[48] F. Tao, "Research on the application of hydraulic blasting technique in smooth blasting of highway tunnel," Architectural Engineering Technology And Design, no. 8, pp. 1116-1116, 2016.

[49] H. B. Zhao, Z. W. Wang, H. Zhang, and W. Li, "Effect of dynamic loads on development of internal microstructure and distribution of new surface fractures of coal," Chinese Journal of Rock Mechanics and Engineering, vol. 35, no. 5, pp. 971-979, 2016.

[50] G. H. Zhang, Z. L. Li, K. Y. Nie, and M. H. Liu, "Experimental study on fracture toughness of concrete with different moisture contents," Journal of Hydraulic Engineering, vol. 35, no. 2, pp. 109-116, 2016.

[51] Y. G. Chen and M. G. Qian, Strata Control around Coal Face in China, Coal Industry Press, Beijing, 1994.

[52] L. M. Dou and X. Q. He, Prevention and Control of Rock Burst in Coal Mine, China University of Mining and Technology Press, Xuzhou, 2001.

[53] L. M. Dou, S. G. Cao, Z. T. Liu, X. R. Wu, and W. Z. Cao, "Analysis on the impact of hard roof on rock burst in sanhejian coal mine," Journal of China University of Mining \& Technology, vol. 32, no. 4, pp. 388-392, 2003.

[54] Z. Y. Wang, L. M. Dou, G. F. Wang, and J. Li, "Research on dynamic response of anchoring roadway surrounding rock structure," Journal of China University of Mining \& Technology, vol. 45, no. 6, pp. 1132-1140, 2016.

[55] H. D. Li, H. Lan, T. T. Du, and D. J. Hou, "Micro-seismic characteristic and danger-relief method in rock-burst danger period of mining face under hard and thick roof of kuangou mine," Journal of China Coal Society, vol. 38, no. S1, pp. 611, 2013.

[56] A. Y. Cao, Research on Seismic Effort of Burst and Failure of Coal-Rock Mass Associated with Mining and Its Application, Dissertation, China University of Mining and Technology, 2009.

[57] Y. Yu, Dynamic Characteristic of Hard Roof Fracture in ExtraThick Coal Seam and Its Application on the Control of Roadway Surrounding Rock, Dissertation, China University of Mining and Technology, 2015. 